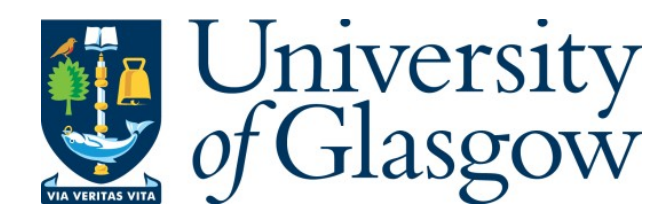

Thomson, N. C. (2016) Addressing corticosteroid insensitivity in adults with asthma. Expert Review of Respiratory Medicine, 10(2), pp. 137-156.

There may be differences between this version and the published version. You are advised to consult the publisher's version if you wish to cite from it.

http://eprints.gla.ac.uk/120917/

Deposited on: 15 July 2016

Enlighten - Research publications by members of the University of Glasgow http://eprints.gla.ac.uk 


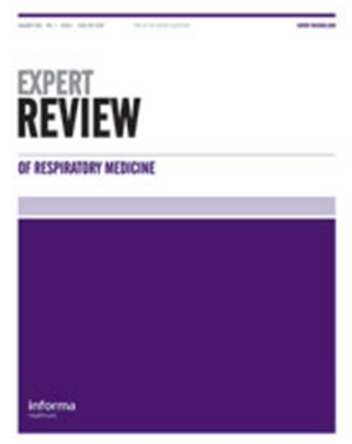

\section{Addressing corticosteroid insensitivity in adults with asthma}

\begin{tabular}{|r|l|}
\hline Journal: & Expert Review of Respiratory Medicine \\
\hline Manuscript ID & ERRX-2015-0097.R1 \\
\hline Manuscript Type: & Reviews \\
\hline Keywords: & $\begin{array}{l}\text { Adherence, Asthma, Biologic agents, Biomarkers, Cigarette smoking, } \\
\text { Corticosteroids, Corticosteroid insensitivity, Corticosteroid resistance, Small } \\
\text { molecule drugs }\end{array}$ \\
\hline \multicolumn{2}{|l}{} \\
\hline
\end{tabular}

SCHOLARONE ${ }^{m}$

Manuscripts 


\title{
Title: Addressing corticosteroid insensitivity in adults with asthma
}

\author{
Abstract \\ Corticosteroids are the most effective treatment for asthma, but the therapeutic response \\ varies markedly between individuals, with up to one third of patients showing evidence of \\ insensitivity to corticosteroids. This article summarizes information on genetic, environmental \\ and asthma-related factors as well as demographic and pharmacokinetic variables associated \\ with corticosteroid insensitivity in asthma. Molecular mechanisms proposed to explain \\ corticosteroid insensitivity are reviewed including alterations in glucocorticoid receptor \\ subtype, binding and nuclear translocation, increased proinflammatory transcription factors \\ and defective histone acetylation. Current therapies and future interventions that may \\ restore corticosteroid sensitivity in asthma are discussed, including small molecule drugs and \\ biological agents. In the future, biomarkers may be used in the clinic to predict corticosteroid \\ sensitivity in patients with poorly controlled asthma.
}

Word count: 120 words

Key words: Adherence; asthma; biological agents; biomarkers; cigarette smoking; corticosteroids; corticosteroid insensitivity; corticosteroid resistance; small molecule drugs. 


\section{Introduction}

Asthma is a chronic inflammatory disease of the airways that affects 300 million people worldwide. Both national and international guidelines recommend daily inhaled corticosteroid as the preferred controller treatment for adults and adolescents with asthma who have poor symptom control or who at risk of exacerbations [201,202]. Inhaled corticosteroid use in asthma reduces symptoms, improves quality of life and increases lung function as well as decreases the rate of exacerbations [201, 202]. The majority of the therapeutic benefits of inhaled corticosteroids are achieved at low to medium doses [1], although higher doses are often required in patients with more severe asthma [2] [202]. Short courses of oral corticosteroids are administered to treat severe exacerbations and daily oral corticosteroids are used in the lowest dose providing adequate control to treat patients with severe asthma when symptoms are uncontrolled despite maximal therapy [201, 202].

Guideline recommendations for inhaled and oral corticosteroid use in asthma are based on average therapeutic responses from clinical trial populations that may not be representative of 'real-life' patients [3]. Numerous studies in adults and children with asthma have noted a considerable patient-to-patient variability in improvements in lung function and airway hyperreactivity with inhaled and oral corticosteroid treatment in patients with apparently similar levels of disease severity [4-6] (Figure 1). The findings from these studies suggest that corticosteroid insensitivity may be present in approximately one third of patients with asthma. Inhaled corticosteroids exhibit a linear dose-response for systemic adverse effects [7] and high doses are associated with adrenal suppression $[1,8]$, reduced bone mineral density and increased risk of fractures as well as diabetes and reactivation of tuberculosis [9]. To improve the 
therapeutic ratio for corticosteroid use in asthmatic patients who have an impaired clinical responses to corticosteroids there is a need to understand the causes of corticosteroid insensitivity and how best to manage these patients. This article reviews published information on factors associated with corticosteroid insensitivity in asthma, considers the molecular mechanisms proposed to explain corticosteroid insensitivity and discusses current therapies and future interventions that may restore corticosteroid sensitivity in asthma.

\section{Factors associated with corticosteroid insensitivity in asthma}

Corticosteroid insensitivity is an imprecise term used to describe an impaired response to corticosteroids, whereas corticosteroid resistance implies the absence of any response to corticosteroids. A range of in vivo and in vitro biomarkers have been used to assess the response to corticosteroids in man, although none are ideal. The variation in corticosteroid sensitivity in people with asthma is most commonly measured using clinical outcomes such as symptoms, lung function and exacerbations [6]. A composite phenotype that includes information on inhaled corticosteroid treatment response in patients with mild to moderate asthma assessed by six outcomes (lung function, bronchodilator response, airway responsiveness, symptoms, need for oral corticosteroids and frequency of emergency department visits and hospitalizations) is reported to identify endophenotypes that more accurately describe corticosteroid sensitivity [10]. Sputum eosinophils, transcription factor gene expression levels on airway cells [11] and exhaled nitric oxide [12] as well as bronchial allergen challenge [13], exhaled breath profiling [14], urinary biomarkers [12] and the cutaneous vasoconstrictor response to topical corticosteroid [15] have been employed to measure variability in corticosteroid sensitivity in asthma. In vitro tests of corticosteroid 
induced suppression of peripheral blood mononuclear cell (PBMC) T lymphocyte proliferation [16] and expression of transcription factors on cells $[16,17]$ or composites in vitro measurements [18] have be used as biomarkers of corticosteroid sensitivity, although the ability of these tests to predict clinical responses to corticosteroids in the general population of patients with asthma is uncertain.

Genetic, environmental and asthma associate factors as well as demographic and pharmacokinetic variables may contribute to differences in sensitivity to corticosteroids between people with asthma (Table 1). Variations in corticosteroid sensitivity are also found in healthy people.

\section{Genetic factors}

Genetic variants of the glucocorticoid receptor (GR) gene are implicated in differences in corticosteroid sensitivity in healthy subjects and some inflammatory diseases, although GR polymorphisms have not been reported in corticosteroid resistant asthma. Single-nucleotide polymorphisms (SNPs) of genes affecting the corticosteroid pathway have been described in children with asthma recruited to the Childhood Asthma Management Program (CAMP) and in replication populations. The CAMP study followed children with asthma who were treated with inhaled corticosteroids over a 4-year period with efficacy outcomes including improvements in $\mathrm{FEV}_{1}$, airway responsiveness to methacholine and the protection from exacerbations [19]. SNP variants associated with altered therapeutic response to treatment with inhaled corticosteroids include T-box expressed in T cells21 (TBX21) [20], corticotrophinreleasing hormone receptor 1 gene (CRHR1) [21], low-affinity IgE receptor gene (FCER2) [22] 
and glucocorticoid-induced transcript 1 gene (GLCCI1) [23]. Genome-wide association studies (GWAS) have identified novel pharmacogenetic loci associated with variations in response to inhaled corticosteroids including T gene SNPs [24] and SNPs chr6 rs6924808 and chr11 rs1353649 [25]. Genes implicated in fetal lung development are also associated with corticosteroid treatment response [26]. The contribution of a single SNP to explaining corticosteroid insensitivity in the total asthma population is likely to be small, whereas combinations of polymorphisms in corticosteroid sensitive genes may have a more important effect on the therapeutic response to corticosteroids.

\section{Environmental factors}

\section{Cigarette smoke}

Corticosteroid insensitivity is an important clinical feature of current smokers with asthma [27-31]. Asthmatic smokers are less responsive to short and medium term treatment with inhaled or oral corticosteroids when assessed by improvements in symptoms, lung function and exacerbation rates compared to asthma patients who do not smoke [27-32]. Long-term treatment with inhaled corticosteroids however, may have beneficial effects in smokers with asthma by reducing the rate of decline in lung function [32-35]. Although insensitivity to inhaled corticosteroids is likely to contribute to poor asthma control in smokers, there are a number of unresolved issues regarding this phenomenon including the observation that not all smokers with asthma show insensitivity to short-term corticosteroid therapy, possibly due to differences in airway inflammation or intensity of smoking. The relationship between the intensity of exposure to cigarette smoke, either daily or cumulatively, and the development of corticosteroid insensitivity is not clearly established. Most studies that report a reduced 
responsiveness to corticosteroids have recruited patients with a heavy smoking history of greater than 10 pack years.

\begin{abstract}
A history of exposure to secondhand smoke in utero is associated with a reduced improvement in airway responsiveness to inhaled corticosteroids in children recruited to the CAMP study [36]. The mechanism underlying the attenuated response to inhaled corticosteroids in not known, although exposure to secondhand smoke in utero may adversely affect both the structure and function of the airways.
\end{abstract}

\title{
Allergen exposure
}

GR binding affinity of PBMCs from ragweed sensitive asthmatic subjects is reduced during the ragweed season when compared to before and after the pollen season [37]. In contrast, natural exposure to birch pollen does not reduce the ability of glucocorticoids to inhibit granulocyte-macrophage colony-stimulating factor production from PBMCs from subjects with seasonal allergic asthma and rhinitis due to birch pollen [38]. Severe asthma in children with fungal sensitization is associated with elevated airway interleukin (IL)-33 concentrations, which has been shown to induce corticosteroid insensitivity in a mouse model of asthma after exposure to the fungus Alternaria alternata [39]. Based on the current evidence, the importance of allergen exposure in corticosteroid insensitivity in vivo in asthma remains to be clearly established.

\section{Infections}

Toxins expression by microbes, called superantigens, are proposed as a possible mechanism by which infection could induce corticosteroid insensitivity [40]. Superantigens inhibit 
corticosteroid-induced translocation of GR $\alpha$ to the cell nucleus [40] and increase the numbers of nonfunctioning GR $\beta$ [41]. Alteration to the airway microbiome has been implicated in corticosteroid responsiveness in asthma [42]. Corticosteroid-resistant asthma is associated with classical antimicrobial activation of airway macrophages [43] and expansion of specific gram-negative bacteria, which in vitro induce activate of mitogen-activated protein kinase (MAP) and corticosteroid insensitivity [42]. In a mouse model, the microbial agonists lipopolysaccharide (LPS) and $\beta$-glucan act synergistically with house dust mite to induce a corticosteroid insensitive neutrophilic inflammation though toll-like (TL)-4 and dectin-1 receptors [44].

Virus-induced exacerbations including rhinovirus infection are insensitive to treatment with corticosteroids, especially in children with asthma [45]. Rhinovirus infection causes corticosteroid insensitivity in airway epithelium through induction of nuclear factor $\mathrm{KB}$ (NFKB) and c-Jun N-terminal kinase (JNK) activation [46] and in monocyte cell lines through a reduction in histone deacetylase (HDAC)2 activity [47]. The clinical importance of superantigens, the airway microbiome and viruses in inducing corticosteroid resistance in asthma remains to be established.

\section{Endotoxin}

Increased sputum endotoxin concentrations are associated with an impaired lung function response to oral corticosteroids, particularly in never smokers with asthma, which suggests that airway endotoxin may contribute to corticosteroid insensitivity in asthma [48] (Figure 2). Patients with asthma may be exposed to endotoxin in household dust, through certain occupations such as cotton textile workers or farm animal workers and in cigarette smoke, 
either as active smokers or by exposure to secondhand smoke. Increased bacterial load within the airways or increased airway permeability might also increase airway endotoxin concentrations in asthma.

\author{
Vitamin D deficiency \\ Reduced vitamin D concentration in asthma are associated with reduced lung function, \\ increased airway hyperresponsiveness and impaired corticosteroid sensitivity, when \\ measured by dexamethasone-induced expression of mitogen-activated protein kinase \\ phosphatase (MKP)1 by PBMCs [49].
}

\title{
Asthma associated factors
}

\section{Airway inflammatory cell phenotypes and airway remodeling}

Eosinophilic airway inflammation, identified by the presence of sputum or blood eosinophilia, predicts patients with asthma who are likely to obtain a favorable therapeutic response to corticosteroids. The type 2 helper T-cell $\left(\mathrm{Th}_{2}\right)$-high subtype of asthma is associated with increased epithelial expression of interleukin (IL)-4, IL-5 and IL-13 [11] and predicts a beneficial therapeutic response to corticosteroids [11]. Many patients with asthma have noneosinophilic asthma, sometimes associated with neutrophilic inflammation and/or have a $\mathrm{Th}_{2}$-low type of inflammation. Non-eosinophilic inflammation is associated with an impaired therapeutic response to inhaled corticosteroids [50,51], although the lack of efficacy may not be complete. Intermittent eosinophilia might be a factor accounting for corticosteroid sensitivity in some of this group [51]. The numbers of peripheral blood CD8(+) T cells expressing the leukotriene $\mathrm{B}_{4}\left(\mathrm{LTB}_{4}\right)$ receptor $\mathrm{BLT} 1$ are increased in corticosteroid resistant 
asthma [52]. Increased reticular basement membrane (RBM) thickness, which is a

pathologic feature of airway remodelling, is associated with an impaired improvement in $\mathrm{FEV}_{1}$ after a short course of systemic corticosteroids in severe asthma [53].

\section{Corticosteroid resistant asthma}

A very small proportion of patients with severe asthma have corticosteroid resistant asthma defined by less than a $15 \%$ improvement in $\mathrm{FEV}_{1}$ after 2 weeks of prednisolone at a dose of 40 mg daily. Using an alternative definition of corticosteroid resistance, based on an increase in morning peak expiratory flow (PEF) of $\leq 15 \%$ following a course of oral corticosteroid, a retrospective study of 784 subjects with poorly controlled asthma found that $26 \%$ of subjects fulfilled this definition of corticosteroid resistant asthma [5].

\section{Non-adherence and poor inhaler technique}

Non-adherence with anti-asthma treatment is one of the most important reasons for poor symptom control and apparent corticosteroid insensitivity [54], with around a quarter of exacerbations estimated to be due to non-adherence with inhaled corticosteroids [55]. A high proportion of patients with difficult to control asthma have poor adherence with prescribed therapy, including both inhaled and oral corticosteroids [56]. Only a small percentage of inhaled corticosteroid reaches the target area in the lung, with the majority lost in the oropharynx or swallowed following inhalation. Good technique is paramount to ensure the benefits of inhaled corticosteroid treatment, although around half of all patients have poor inhaler technique irrespective of the device used [202]. 


\section{Concomitant disease and misdiagnosis}

Several concomitant conditions can contribute to poor symptom control or result in misdiagnosis and these should be considered in the event of a poor response to treatment including corticosteroids. For example, psychological factors are associated with worse clinical outcomes in asthma and psychosocial stress has been proposed to induce corticosteroid insensitivity in patients with asthma due to impaired GR expression and/or function [57]. The therapeutic response to corticosteroids in patients considered to have the asthma-COPD overlap syndrome is not clearly established, but in some patients there may be an impaired response.

\section{Demographic variables}

\section{Age and gender}

Age is positively correlated with increased in vitro peripheral blood T lymphocyte resistance to corticosteroids [58]. In Asthma Clinical Research Network (ACRN) trials in non-smokers with mild to moderate asthma, treatment failures (worsening asthma resulting in systemic corticosteroid use, hospitalization, emergency department visit, prolonged decrease in PEF, increase in albuterol use, or safety concerns including exacerbations) increased for every year above age 30 years in participants receiving inhaled corticosteroids [59]. The study did not specifically assess corticosteroid sensitivity. In the same analysis there was no difference in treatment failures between males and females [59].

Race 
In black people with asthma the in vitro suppressive effects of dexamethasone on PBMC T lymphocyte proliferation and transcriptional gene expression responses are impaired compared to white people with asthma $[16,58]$. These findings suggest that a racial predisposition to impaired corticosteroid responsiveness could contribute to worse asthma control. In contrast, patients with mild to moderate asthma recruited to ACRN clinical trials treated with inhaled corticosteroids alone had no more treatment failures including exacerbations in African-Americans compared with white participants [60]. In a study of adolescents and adults with asthma, the proportion of African-Americans was not significantly associated with responsiveness to six weeks treatment with inhaled beclometasone [61].

\section{High BMI}

Mild or moderate asthmatic patients with a high body mass index (BMI) are less likely to achieve asthma control with inhaled fluticasone propionate treatment for 12 weeks compared to patients with a normal BMI [62] and have a smaller reduction in exhaled nitric oxide levels with inhaled corticosteroid treatment [63]. Dexamethasone induced MKP-1 expression in vitro is blunted in PBMCs and bronchoalveolar lavage (BAL) cells in overweight and obese patients with asthma [64]. A cluster analysis of adults with symptomatic airflow obstruction identified an obese-comorbid phenotype with late-onset asthma that obtained improvement in quality of life, although not in PEF variability, after inhaled corticosteroids [65].

\section{Pharmacokinetics of corticosteroids}


Impaired access of inhaled corticosteroids to target cells in the airways could result in corticosteroid insensitivity. Airway mucosal permeability, which is increased in both normal smokers and in asthma or excess mucus lining the airways of asthmatic smokers could impair the pharmacokinetics of inhaled corticosteroids. Dysfunction of small airways is thought contribute to poor symptom control in severe asthma and in smokers with asthma and due to the reduced deposition of large particle inhaled corticosteroids to the small airways might contribute to corticosteroid insensitivity. The particle size of dry powder fluticasone propionate is increased in the presence of tobacco smoke and based on this finding it has been postulated that cigarette smoking could prevent the dispersion of corticosteroid into the small airways of the lung and hence inhaler efficacy [66]. The pharmacokinetics of oral prednisolone in asthma is similar to healthy controls [67].

\section{Mechanisms of corticosteroids insensitivity}

Corticosteroids are the most effective treatment for asthma through their inhibitory actions on inflammatory cells and pathways involved in the pathogenesis of the disease [68]. Corticosteroids reduce inflammation through activation of GRs in the cytoplasm of target cells. The activated GR-corticosteroid complex binds to glucocorticoid-responsive elements (GREs) in the promoter region of corticosteroid-responsive genes within the nucleus to suppress (transrepression) or induce (transactivation) glucocorticoid target genes. Transrepression is believed to be responsible for the majority of the anti-inflammatory activity of corticosteroids through the reduced synthesis of proinflammatory transcription factors and by preventing the stimulation of inflammatory genes. The molecular mechanisms for the anti-inflammatory effects of corticosteroids are complex and not fully elucidated [69]. 
However, a key mechanism is thought to involve the reversal of histone acetylation of activated inflammatory genes through ligand-bound GRs binding to co-activator molecules and subsequent recruitment of HDAC2 to the activated inflammatory gene transcription complex [68]. Recent studies suggest that the production of anti-inflammatory proteins may have a more important role in resolution of inflammation than previously considered [69]. Corticosteroids induce histone acetylation of anti-inflammatory genes (transactivation), including MKP-1 and glucocorticoid-inducible leucine zipper 1 (GILZ-1) as well as potentiating the effects of $\beta_{2}$ agonists, in part through increased expression of $\beta_{2}$ adrenergic receptors on cell surfaces [68]. The adverse effects of corticosteroids are thought to be due to transactivation of genes involved in glucose, lipid and muscle metabolism as well as by interacting with negative GREs to inhibit the production of osteocalcin, which is involved in bone synthesis [68]. Corticosteroids also exert anti-inflammatory effects through a nongenomic mechanism, which has a rapid onset within minutes, is of short duration and is dosedependent. Non-genomic mechanisms are thought to include activation of endothelial nitric oxide synthase (eNOS) resulting in the production of nitric oxide (NO) and the release of the anti-inflammatory molecule annexin-1.

Several mechanisms could explain the variation between people in the response to corticosteroids including differences in genetic, inflammatory cell phenotypes and other factors discussed in section 2. Molecular mechanisms of corticosteroid insensitivity in asthma have been extensively reviewed in previous publications [70-72] and only a summary of the key mechanisms are reviewed in this article. Postulated molecular mechanisms for corticosteroid insensitivity in asthma include alteration in GR subtypes, defective GR binding 
and impaired GR nuclear translocation, increased proinflammatory transcription factors and defective histone acetylation (Table 2).

\section{Alteration in glucocorticoid receptor subtypes}

$\mathrm{GR} \alpha$ is a functional receptor that binds corticosteroids to induce or suppress the transcription of multiple genes and is the predominant GR in most inflammatory cells. Isoforms of GR are derived by alternative splicing and one subtype GRß is unable to bind corticosteroids. It has been proposed that corticosteroid insensitivity in asthma occurs due to over expression of the non-functional GR $\beta$ subtype or a reduction in ligand-activated GR $\alpha$ subtype numbers or activity. GRß expression on cells is increased by several factors associated with corticosteroid insensitivity in asthma including superantigens [41] and proinflammatory mediators [73] as well as by cigarette smoking, where the ratio of $G R \alpha$ to GR in PBMCs is reduced in cigarette smokers compared with never smokers [74]. Elevated GR $\beta$ expression in corticosteroidresistant asthma may reduce nuclear translocation of $\mathrm{GR} \alpha$ and decrease HDAC2 expression in response to corticosteroids [75]. Overall the data is conflicting on the importance of alterations in the GR $\beta$ subtype in causing corticosteroid insensitivity in asthma $[75,76]$. A cluster analysis of patient with mild to moderate asthma reported that obese subjects have reduced expression of GCR $\alpha$ in PBMCs that correlates with a reduced induction of MKP-1 expression by dexamethasone [77].

\section{Defective glucocorticoid receptor binding and nuclear translocation}


A reduction in GR binding affinity and nuclear translocation could contribute to corticosteroid insensitivity through the action of pro-inflammatory mediators, such as IL-2 and IL-4 in combination or IL-13. Cytokines are thought to induce these effects by phosphorylation of GR through the activation of protein kinases including P38 MAPK, JNK and extracellular signal-regulated kinase (ERK) [71]. Corticosteroids activate endogenous inhibitors of p38MAPK and JNK pathways including MKP-1 and protein phosphatase 2A (PP2A) $[71,78]$. The expression of the anti-inflammatory protein MKP-1 is reduced in alveolar macrophages from patient with severe asthma associated with corticosteroid insensitivity [79] and in PBMCs from overweight and obese patients with asthma $[64,77]$. In a mouse model, the translocation of GR to the nucleus is inhibited by IFN- $\gamma$ producing cells and LPS cooperating to produce IL-27 from macrophages through activation of toll-like receptor (TLR)4 and MyD88 dependent pathways [80]. Furthermore, IFN- $\gamma$ and LPS induce miR-9 expression in lung tissue and primary macrophages, which reduces PP2A activity [81]. Corticosteroid induced GR $\alpha$ nuclear translocation is suppressed by rhinovirus infection in airway epithelium through JNK activation [46]. Recently asthmatic children clinically classified as poor corticosteroid responders were reported to have reduced GR bioavailability due to decreased GR protein expression and more rapid corticosteroid-induced down regulation compared to asthmatic children classified as good corticosteroid responders [82].

\section{Increase in proinflammatory transcription factors}

Activation of pro-inflammatory transcription factors such as NF- $\kappa \mathrm{B}$, activator protein-1 (AP-1) and signal transduction-activated transcription factors (STAT) enable the translation of inflammatory genes and recruiting of inflammatory cells and could cause corticosteroid 


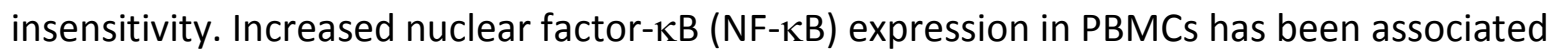
with corticosteroid insensitivity in severe asthma [83] and as tobacco smoke activates NF- $\kappa$ B, this transcription factor which might contribute to reduced response to corticosteroids in smokers with asthma. Dysregulation of AP-1 is associated with corticosteroid resistant asthma [84]. Rhinovirus infection induce corticosteroid resistance in airway epithelium by the activation of NF-KB [46].

\section{Defective histone acetylation}

Corticosteroids require HDAC activity for maximal suppression of inflammatory cytokine induction [85]. Low levels of HDAC2 expression are found in PBMCs [86] and alveolar macrophages [87] in patients with severe asthma, which is thought to be due to excessive oxidative stress [71]. Smokers have decreased HDAC2 activity in alveolar macrophages, possibly as a result of oxidative and nitrative stress and this may lead to increased inflammatory gene expression and reduced sensitivity to corticosteroids $[88,89]$. Oxidative stress activates phosphinositide 3-kinase (PI3K) resulting in AKt phosphorylation and HDAC2 inactivation [71].

\section{Other immune mechanisms}

Suppression of the anti-inflammatory cytokine IL-10 production by T lymphocytes in asthma could contribute to corticosteroid insensitivity [90]. The pro-inflammatory mediator TNF $\alpha$ induces corticosteroid insensitivity in a mouse model of neutrophilic airway inflammation [91]. 


\section{Current management of corticosteroid insensitivity}

The aims of management are to achieve good asthma control and to minimize treatment burden, especially from oral corticosteroid use, although achieving these aims in severe asthma is often difficult. A step-wise approach to treatment should be integrated into a management plan that includes assessment of adherence and inhaler technique, non-pharmacological treatments where appropriate, as well as supported self-management [201, 202]. It is important to distinguish patients with severe asthma from those with 'difficult to control' asthma due to reasons other than disease severity by undertaking a systematic evaluation [92]. For adults and adolescents with asthma patients who have poor symptom control or who at risk of exacerbations and in whom the diagnosis of asthma has been confirmed, guidelines recommend daily inhaled corticosteroid as the preferred controller treatment, with the addition of add-on therapies if symptoms remains poorly controlled [201, 202]. However, this approach may result in up to one third of patients failing to obtain maximal improvement in asthma control and quality of life due to corticosteroid insensitivity. Several management strategies that address specific factors associated with an impaired therapeutic response to corticosteroids may result in improvements in asthma control (Table 3).

\section{Non-adherence}

The ability to detect poor adherence based on history alone is poor. Adherence can be assessed by reviewing prescription refill frequency and by measuring circulating blood prednisolone concentration in patients taking oral corticosteroids. A trial of a parenteral depo corticosteroid can help establish whether persistent symptoms are due to poor adherence with inhaled and/or 
oral corticosteroids. Strategies to improve adherence include adequate explanation of the indications for treatment, discussion of real and perceived concerns of adverse effects of treatment, simplifying drug treatment regimens, reminders and reinforcement [54]. Improving medication adherence could have a substantial beneficial impact on asthma related clinical outcomes [93].

\title{
Non-pharmacological interventions
}

There is limited information on the effectiveness of non-pharmacological interventions for the management of factors associated with corticosteroid insensitivity in asthma (Table 1). A small number of studies have examined the role of smoking cessation on asthma outcomes and reported improvements in symptoms and lung function in those people who quit smoking successfully [30]. Smoking cessation in asthma is associated with improvement in corticosteroid sensitivity $[15,94]$. Weigh reduction in asthmatic patients with a high BMI may result in improvements in asthma symptoms [95], although whether corticosteroid sensitivity also improves is not reported.

\begin{abstract}
Anti-inflammatory and corticosteroid-enhancing actions of vitamin D are reported in monocytes of patients with corticosteroid-resistant asthma and those with steroid-sensitive asthma, although the responses to corticosteroids remains lower than in patients with corticosteroid sensitive asthma $[96,97]$. Peripheral blood CD4+ T cells isolated from subjects with corticosteroid-resistant asthma regain their sensitivity to corticosteroids following a short course of oral vitamin D through the induction of IL-10 [98]. Based on these findings, several clinical trial have examined the effect of dietary supplement of vitamin D in asthma. A small clinical trial of vitamin D3 supplementation
\end{abstract}


in patients with corticosteroid resistant asthma demonstrated a modest improvement in lung function after a short course of oral prednisolone and an increase in dexamethasone-induced IL-10 production in vitro as well as suppression of dexamethasone-induced IL-17A production $[99,100]$. Two large randomized clinical trials of vitamin D3 supplementation in patients with asthma and vitamin D insufficiency [VIDA and ViDiAs trials), although not selected for corticosteroid insensitivity, reported no improvements in clinical outcome $[101,102]$. Interestingly, vitamin D supplementation reduced eosinophilic inflammation in patients with non-atopic asthma, suggesting that certain phenotypes might obtain benefit from vitamin D3 supplementation [103].

\title{
Current pharmacological treatments
}

\begin{abstract}
A step-up in the dose of corticosteroid as well as the addition of other therapies may benefit individuals with asthma that is associated with corticosteroid insensitivity.
\end{abstract}

\section{Inhaled corticosteroids}

The relatively flat dose response to inhaled corticosteroids in asthma results in the majority of the therapeutic benefits being achieved at low to medium doses [1]. In the Gaining Optimal Asthma Control (GOAL) trial, high dose inhaled corticosteroids treatment with inhaled fluticasone propionate 1000 mcg daily resulted in clinical improvements in asthma control, although in patients with more severe disease only $50 \%$ achieved well controlled asthma and $20 \%$ achieve totally control [2] [201]. In a short-term study in smokers with mild asthma who demonstrated corticosteroid insensitivity to low dose inhaled corticosteroids there was an improvement in lung function with high dose inhaled corticosteroid treatment [31]. Targeting the small airways with extrafine-particle inhaled corticosteroids may 
potentially impact favorably on the safety and efficacy of inhaled corticosteroids through improved total lung deposition and resulting in improved asthma control at lower daily doses than the large-particle inhaled corticosteroid. Observational studies suggest that extrafine particle HFA-BDP Qvar ${ }^{\circledR}$ may achieve better control at lower prescribed doses than large particle inhaled corticosteroids [104], but to date randomized controlled trials have not clearly demonstrated that equipotent doses of small-particle inhaled corticosteroids are more effective than large-particle inhaled corticosteroids.

\section{LABAs in combination with inhaled corticosteroids}

The combination of a LABA and an inhaled corticosteroid may act synergistically to increase corticosteroid sensitivity of inflammatory cell in severe asthma and in smokers with asthma. Long acting $\beta_{2}$-agonists have been shown in vitro to increase the translocation of GRs to the nucleus. The LABA formoterol increases corticosteroid sensitivity in vitro through inhibition of GR phosphorylation via PP2A activation in a $\beta_{2}$-receptor independent manner [105] and by inhibition of PI3K signaling [106]. In addition, formoterol enhances the expression of the anti-inflammatory transcription factor MKP-1 induced by corticosteroids [107].

\section{Low dose theophylline}

Low dose theophylline restores corticosteroid sensitivity in-vitro possibly by increasing HDAC2 activity, which is suppressed in severe asthma and in smokers and a similar clinical effect might occur in asthma[108]. An exploratory study examined the impact of low dose theophylline added to inhaled corticosteroid compared to inhaled corticosteroid alone in a group of smokers with asthma [109] (Figure 3). The addition of theophylline to inhaled corticosteroid, at a dose titrated to provide a 'sub-therapeutic' concentration, resulted in 
increased efficacy as measured by lung function and suggested the restoration of corticosteroid sensitivity in those treated with the combination. Theophylline inhibits oxidative stress dependent PI3K- $\delta$ activation and restores corticosteroid sensitivity in PBMCs from patients with COPD [108]. Clinical trials have not investigated the therapeutic effects of adding low dose theophylline in patients with severe asthma. A fixed combination of ultralow dose of theophylline with fluticasone, SKP-2075 is under development for the treatment COPD. This combination would potentially be of benefit in the treatment of corticosteroid insensitivity in severe asthma and in smokers with asthma.

\section{Leukotriene-receptor antagonist}

A randomized controlled trial that compared oral montelukast (10 mg daily), inhaled fluticasone propionate (500 $\mu \mathrm{g}$ daily), and placebo over a 6-month treatment period in mild smokers with asthma [110] reported that less than 50 percentage of days with asthma control during each treatment, although both active treatments were better than placebo. Patients with a smoking history of $\leq 11$ pack years tended to show greater benefit with fluticasone, whereas those with a smoking history of $>11$ pack years tended to show greater benefit with montelukast.

\section{Oral corticosteroid sparing therapies}

Some biological agents and immunosuppressive agents have oral corticosteroid sparing effects in patients with severe asthma who have uncontrolled symptoms despite treatment that includes high dose inhaled corticosteroids and LABAs, although it is unclear whether the reduction in daily oral corticosteroids is due to a reversal of corticosteroid insensitivity or due to the intervention targeting corticosteroid insensitive inflammatory pathways. Omalizumab is a humanised 
monoclonal antibody that binds circulating IgE antibody produces improvements in quality of life and reductions in exacerbations [111] as well as possibly having oral corticosteroid-sparing effects. An anti-IL-5 monoclonal antibody mepolizumab, which blocks the binding of IL-5 to IL-5 receptor- $\alpha$ on the surface of eosinophils, decreases severe exacerbations [112] and reduces the use of oral corticosteroids [113]. Mepolizumab was recently licensed in the US for use in patients with severe eosinophilic asthma.

\title{
5. Potential future therapies for corticosteroid insensitivity
}

\author{
Many patients with asthma that is associated with corticosteroid insensitivity continue to have \\ poorly controlled disease despite treatment with currently available therapies. There is an unmet \\ need for new treatments that will impact favorably on clinical outcomes in these patients \\ through the restoration of corticosteroid sensitivity (Table 4). Novel small molecule drugs and \\ biologics agents have been developed as possible new treatments for asthma, including for \\ patients with corticosteroid insensitivity. Several drugs licensed for the treatment of medical \\ conditions other than asthma have been investigated for their efficacy in asthma. Candidate \\ drugs have been chosen usually because of pre-clinical evidence of effects on reduction \\ inflammation and restoring corticosteroid sensitivity that might be relevant to the treatment of \\ asthma. Potential therapies for patients with severe refractory asthma associated with \\ corticosteroid insensitivity are summarized below.
}




\section{Small molecule drugs}

\section{Macrolides}

The mechanism(s) of action of macrolides in the treatment of airway diseases is not established, but could be due to their antibacterial and/or anti-inflammatory actions, which include inhibition of NF-KB and other transcription factors as well as reduction in IL-8 production, neutrophil migration and/or function $[114,115]$. Additionally, macrolides may restore corticosteroid sensitivity by inhibiting PI3K activation [116] and TNF $\alpha /$ IL-17 immune responses [117]. Two recent exploratory clinical trials have investigated the effects of macrolides in non-eosinophilic asthma associated with corticosteroid insensitivity. In the first trial, seventy-seven smokers with mild to moderate asthma were randomized to a double-blind parallel-group trial comparing azithromycin [250 mg per day] with placebo [118]. At 12 weeks, treatment with azithromycin did not improve symptom control or lung function. In the second randomized controlled trial nonsmokers with exacerbation-prone severe asthma received low-dose azithromycin $(n=55)$ or placebo $(n=54)$ as add-on treatment to combination therapy of inhaled corticosteroids and LABA for 6 months [119]. Azithromycin did not reduce the rate of severe exacerbations and lower respiratory tract infections requiring treatment with antibiotics in the total study population. In a predefined subgroup there was a reduction in the rate of primary endpoints in azithromycintreated patients with non-eosinophilic severe asthma (blood eosinophilia $\leq 200 / \mu$ ) [119]. Novel analogues of macrolides have been developed that have greater anti-inflammatory effects than current macrolides, such as solithromycin (CEM-101) $[115,116]$ or that lack anti-bacterial properties but retain anti-inflammatory activity, such as the non-antibiotic azithromycin derivative CSY0073 [120]. 


\section{Protein kinase inhibitors}

Inhibition of protein kinase, such as p38MAPK, narrow spectrum kinase and tyrosine kinase, that are involved in cellular signaling of pro-inflammatory cytokines, may have a role in the treatment of severe asthma associated with corticosteroid insensitivity [121-123]. Several p38MAPK inhibitors restore corticosteroid sensitivity in PBMCs from patients with severe asthma $[121,124]$ and COPD [125]. Clinical trials of p38MAPK inhibitors, such as oral losmapimod (GW856553) and inhaled AZD7624 are underway in COPD, although none are registered in asthma. A specific ckit tyrosine kinase inhibitor imatinib inhibits hyperresponsiveness, inflammation and remodeling in murine asthma models [126] and is undergoing clinical trial evaluation in severe refractory asthma (ClinicalTrials.gov Identifier: NCT01097694). A tyrosine kinase inhibitor masitinib that targets c-kit and the platelet-derived growth factor (PDGF) receptor improved asthma control in patients with severe corticosteroid-dependent asthma [127] and a further clinical trial is underway in patients with severe persistent asthma treated with oral corticosteroids (ClinicalTrials.gov Identifier: NCT01449162).

\section{PI3kinase inhibitors}

Pre-clinical studies suggest that $\mathrm{PI} 3 \mathrm{~K}-\delta$ inhibitors could potentially reverse corticosteroid insensitivity by increasing HDAC2 activity $[128,129]$. Selective PI3K inhibitors are being developed as novel treatments of corticosteroid insensitive airway diseases. An inhaled PI3K $\delta$ inhibitor GSK2269557 is undergoing clinical trials in adults with persistent uncontrolled asthma (ClinicalTrials.gov Identifier: NCT02567708). PI3K $\delta$ and $\gamma$ isoforms are implicated in inflammatory cell recruitment and activation [129]. An inhaled dual PI3K $\delta / Y$ inhibitor, TG100115 , reduces airway inflammation induced by allergen and cigarette smoke in murine models 
and restores corticosteroid sensitivity in the smoke model [130]. A PI3K $\delta / Y$ inhibitor RV1729 has undergone early stage clinical evaluation in COPD, although no results are published (ClinicalTrials.gov Identifier: NCT02140346). The tricyclic antidepressant nortriptyline reverses corticosteroid insensitivity induced by oxidative stress in vitro by inhibition of $\mathrm{PI} 3 \mathrm{~K}-\delta$ and it has been proposed as a potential treatment for corticosteroidinsensitivity in severe asthma, smokers with asthma and COPD [131].

\author{
NF- $K B$ inhibitors \\ Targeting activation of the pro-inflammatory transcription factor NF- $\kappa B$ with inhibitors of $I \kappa B$ \\ kinases (IKKs) may restore corticosteroid sensitivity in severe asthma and smokers with \\ asthma [132], although adverse effects may limit the use of these compounds.
}

\title{
$P D E_{4}$ inhibitors and dual $P D E_{3}$ and $P E_{4}$ inhibitors
}

Phosphodiesterase $(\mathrm{PDE})_{4}$ inhibitors have immunomodulatory properties relevant to the treatment of asthma including the restoration of corticosteroid sensitivity [133]. The oral PDE 4 inhibitor roflumilast reverses corticosteroid resistance in peripheral blood neutrophils from patients with COPD [134]. High doses of $\mathrm{PDE}_{4}$ inhibitors may be necessary to treat severe asthma, although gastro-intestinal side effects limit their use. Inhaled formulations may improve the therapeutic ratio of $\mathrm{PDE}_{4}$ inhibitors [135-137]. The inhaled $\mathrm{PDE}_{4}$ inhibitor GSK256066 inhibits allergen-induced late asthmatic responses [136] and in patients with moderate COPD GSK256066 was well tolerated although there was no inhibitory effect on inflammatory biomarkers in sputum and blood [138]. The combination of selective $\mathrm{PDE}_{3}$ and $\mathrm{PDE}_{4}$ inhibitors prevent corticosteroid insensitivity induced by oxidative stress in human alveolar macrophages [139]. A 
inhaled dual $\mathrm{PDE}_{3}$ and $\mathrm{PDE}_{4}$ inhibitor, RPL554 has bronchodilator effects and is well tolerated in patients with asthma and COPD [140].

\section{PPARy agonists}

Peroxisome proliferator-activated receptor- $\gamma$ (PPAR $\gamma)$ agonists are members of the nuclear receptor family that exert in pre-clinical studies anti-inflammatory effects potentially relevant to the treatment of airway diseases and to restoring corticosteroid sensitivity [141,142]. A proof of concept study using the oral PPAR $\gamma$ agonist rosiglitazone demonstrated bronchodilator effects in mild to moderate smokers with asthma who had non-eosinophilic inflammation [143]. A borderline reduction in sputum IL-8 was observed with rosiglitazone compared with inhaled beclometasone dipropionate. The adverse-effect profile of oral rosiglitazone has precluded its development as a treatment for asthma. Inhaled PPAR $\gamma$ agonist analogues, such as ADC3277 should facilitate further examination of this potential novel approach to the treatment of corticosteroid insensitive airway disease.

\section{Statins}

Statins reduce cholesterol biosynthesis by inhibiting 3-hydroxy-3-methylglutaryl coenzyme A (HMG-CoA) reductase and in addition have pleiotropic immunomodulatory effects that may be of value for the treatment of chronic inflammatory diseases $[144,145]$. Preclinical in vitro and in vivo studies, including experimental models of allergic [146] and tobacco-smokeinduced lung inflammation [147] found that statins reduce components of airway inflammation potentially relevant to the pathogenesis of asthma and smoke-induced airway diseases. Statins may also restore corticosteroid sensitivity in asthma [148,149]. In smokers with asthma the effects of atorvastatin alone and in combination with inhaled corticosteroid 
was investigated on the ability to suppress the concentration of a range of cytokines, chemokines and growth factors in sputum $[150,151]$. Despite the absence of a suppressive effect of inhaled beclometasone on sputum mediators, atorvastatin either alone or in combination with inhaled beclometasone reduced sputum concentrations of approximately one-third of the selected cytokines, chemokines and growth factors. Atorvastatin significantly reduced sputum concentrations of CCL7, IL-12p70, sCD40L, FGF-2, CCL4, TGF- $\alpha$ and MMP-8 compared with placebo and, when combined with inhaled beclometasone, reduced sputum concentrations of MMP-8, IL-1 $\beta$, IL-10, MMP-9, sCD40L, FGF-2, IL-7, G-CSF and CCL7 compared to inhaled beclometasone alone (Figure 4). Improvements in ACQ and/or AQLQ scores with atorvastatin and inhaled corticosteroid were associated with decreases in G-CSF, IL-7, CCL2 and CXCL8. Interestingly, simvastatin suppresses airway IL-17 and upregulated IL-10 in patients with stable COPD [152]. Taken together, these findings suggest that treatment with atorvastatin either alone or in combination with an inhaled corticosteroid may be of benefit in certain corticosteroid insensitive airway diseases. There is a need for long-term clinical studies examining effect of statins on exacerbations, neutrophil function and airway remodeling in severe asthma associated with corticosteroid insensitivity.

\section{Drugs targeting neutrophilic inflammation}

As increased airway neutrophils have implicated as a potential cause corticosteroid insensitivity in asthma, small molecule drugs have been developed to treat asthma that target these cells including CXCR2 antagonists in asthma [153,154] and COPD [155] and a 5lipoxygenase-activating protein (FLAP) inhibitor GSK2190915 in asthma [156], although their ability to restore corticosteroid sensitivity has not been studied. In addition, evidence for the 
clinical effectiveness of CXCR2 antagonists and FLAP inhibitors in chronic asthma is so far lacking.

\section{Biological agents}

Pre-clinical studies suggest a possible role for $\mathrm{Th}_{17}$ cells and IL-17 in neutrophilic asthma and corticosteroid insensitivity [157]. Increased levels of IL-17 are found in BAL, sputum and bronchial biopsy samples obtained from patients with severe asthma and correlates with sputum neutrophils. Brodalumab is a human monoclonal antibody that binds with high affinity to human IL-17RA, blocking the biologic activity of IL-17A, $-17 \mathrm{~F},-17 \mathrm{~A} / \mathrm{F}$ heterodimer, and IL-25. A randomized clinical trial of brodalumab administered for 12 weeks to 302 adults with inadequately controlled moderate to severe asthma taking regular inhaled corticosteroids found no treatment difference in ACQ score or in secondary endpoints including $\mathrm{FEV}_{1}$ and symptom-free days [158]. In a pre-specified subgroup with high bronchodilator reversibility that accounted for $37 \%$ of the full study population there was a borderline improvement an ACQ score. The clinical trial did not select patients with neutrophilic inflammation. A follow-up clinical trial of brodalumab in inadequately controlled asthma subjects with high bronchodilator reversibility was recently terminated (ClinicalTrials.gov Identifier: NCT01902290). A clinical trial of the IL-17A monoclonal antibody blocker secukinumab in patients with uncontrolled asthma has also been recently terminated (ClinicalTrials.gov Identifier: NCT01478360). Neutralizing TNF $\alpha$ restores corticosteroid sensitivity in a mouse model of neutrophilic airway inflammation [91]. Despite some promise shown in early small clinical studies with the soluble TNF- $\alpha$ receptor blocker etanercept in severe asthma, larger studies with golimumab [159] and etanercept [160] did not confirmed a 
consistent effect. Overall, when combined with concerns over increased risk of severe infections and malignancies with treatment [159] it is unlikely that TNF- $\alpha$ receptor blockers will be developed further for the treatment of asthma. Monoclonal antibodies that block IL-1ß, for example, canakinumab might be of benefit in corticosteroid insensitive asthma, although no clinical studies are currently registered.

\section{Expert commentary}

Corticosteroids are the most effective treatment for asthma, but the therapeutic response differs markedly between individuals. Corticosteroid insensitivity may be clinically important in up to a third of patients with asthma particularly in people with severe disease. Multiple factors including genetic, environmental such as cigarette smoking and asthma-related such as non-adherence and non-eosinophilic inflammation as well as demographic variables are likely to account for the heterogeneous response to corticosteroids between people. Advances in the understanding the molecular mechanisms of corticosteroids have led to important insights into the pathways involved in corticosteroid insensitivity in asthma including alterations in GR subtypes, defective GR binding and nuclear translocation, increased proinflammatory transcription factors and defective histone acetylation as well as other immunological mechanisms. Nevertheless, the underlying mechanisms of corticosteroid insensitivity in asthma are only partly understood. In the future system biology approaches may produce new insights to understanding corticosteroid insensitivity [72].

Non-adherence with inhaled and oral corticosteroid treatment is one of the most important reasons for poor symptom control and apparent corticosteroid insensitivity. There is limited 
information on the effectiveness of non-pharmacological interventions for the management of asthma on specific factors associated with corticosteroid insensitivity in asthma. Advice on smoking cessation is essential in smokers with asthma and may improve corticosteroid responsiveness.

A step-up in the dose of corticosteroid as well as the addition of other therapies for asthma may benefit some individuals with asthma that is associated with corticosteroid insensitivity. High dose inhaled corticosteroids treatment improves clinical outcomes in some patients with severe asthma and in smokers with asthma, but many patients remain symptomatic. Long acting $\beta_{2^{-}}$ agonists have been shown in vitro to increase the translocation of GR to the nucleus and to be of clinical benefit. In an exploratory clinical trial in smokers with asthma low dose theophylline added too inhaled corticosteroid resulted in improvement in lung function and suggested the restoration of corticosteroid sensitivity in those treated with the combination. It is not known whether a similar beneficial effect is achieved with low dose theophylline in severe asthma. Some biological agents such as omalizumab and mepolizumab and immunosuppressive agents such as methotrexate have oral corticosteroid sparing effects in patients with severe asthma although it is not known whether the reduction in daily oral corticosteroids is due to a reversal of corticosteroid insensitivity.

Many patients with asthma continue to have poorly controlled disease that is associated with corticosteroid insensitivity despite receiving treatment with currently available therapies. Small molecule drugs such as macrolides, various protein kinase inhibitors, PI3 kinase inhibitors, NF- $\mathrm{B}$ inhibitors, $\mathrm{PDE}_{4}$ and $\mathrm{PDE}_{3} / \mathrm{PDE}_{4}$ inhibitors, PPAR $\gamma$ agonists as well as statins might be shown to be of benefit in the treatment of corticosteroid insensitive airway diseases. The results of clinical 
trials of biological agents such as monoclonal inhibitors of IL-17 has been disappointing to date. Future clinical trials will determine which of these therapies will ultimately be licensed for the treatment of asthma and in particular will be of value in the treatment of corticosteroid insensitivity.

\section{Five-year review}

The management of patients with asthma is often hampered because it is currently difficult to identify whether poorly controlled symptoms are due to corticosteroid insensitivity or to other reasons such as non-adherence or the involvement of corticosteroid insensitive inflammatory pathways. The development of biomarkers that can identify corticosteroid insensitivity in the clinic would greatly aid in the management of patients with uncontrolled asthma and lead to a personized approach to treatment. Over the last 15 years several international collaborative programmes of research have investigated pathogenic mechanism of severe asthma and corticosteroid insensitivity [161,162]. A recent international collaborate project in severe asthma, the Unbiased Biomarkers for the Prediction of Respiratory Disease Outcome (U-BOPRED) study, is designed to identify new phenotypes/endotypes and treatment targets using omics technologies and applying a system biology approach. It is due to report its main findings shortly [163]. The UK Refractory Asthma Stratification Programme (RASP-UK) is investigating novel biomarker stratification strategies in severe asthma, assessing adherence to corticosteroids and examining biomarkers to optimise corticosteroid treatment [164]. Hopefully the findings from these research networks will identify new approaches to the treatment of patients with severe corticosteroid insensitive asthma. 


\section{Key issues}

- Corticosteroids are the most effective treatment for asthma, but the therapeutic response varies markedly between individuals, with up to one third of patients showing evidence of insensitivity to corticosteroids.

- Multiple factors including genetic, environmental such as cigarette smoking and asthmarelated factors such as non-adherence and non-eosinophilic inflammation as well as demographic and pharmacokinetic variables are likely to contribute to the heterogeneous response to corticosteroids between people.

- Molecular mechanisms proposed to explain corticosteroid insensitivity include alterations in GR $\alpha$ and $\beta$ subtypes, impaired GR binding and nuclear translocation, increased proinflammatory transcription factors and defective histone acetylation.

- Non-adherence with inhaled and oral corticosteroid treatment is one of the most important reasons for poor symptom control and apparent corticosteroid insensitivity.

- There is limited information on the effectiveness of non-pharmacological interventions for the management of asthma on specific factors associated with corticosteroid insensitivity in asthma. Advice on smoking cessation is essential in smokers with asthma and may improve corticosteroid responsiveness.

- A step-up in the dose of corticosteroid as well as the addition of other therapies for asthma may benefit some individuals with asthma that is associated with corticosteroid insensitivity. High dose inhaled corticosteroids treatment improves clinical outcomes in some patients with severe asthma and in smokers with asthma, but many patients remain 
symptomatic. Long acting $\beta_{2}$-agonists have been shown in vitro to increase the translocation of GR to the nucleus. In an exploratory clinical trial in smokers with asthma low dose theophylline added too inhaled corticosteroid resulted in improvement in lung function and suggested the restoration of corticosteroid sensitivity in those treated with the combination.

- Future interventions that may restore corticosteroid sensitivity in asthma include small molecule drugs such as macrolides, several protein kinase inhibitors, PI3 kinase inhibitors, NF- $\mathrm{KB}$ inhibitors, $\mathrm{PDE}_{4}$ and $\mathrm{PDE}_{3} / \mathrm{PDE}_{4}$ inhibitors, PPAR $\gamma$ agonists as well as statins and biological agents.

- In the future, biomarkers may be used in the clinic to predict corticosteroid insensitivity in patients with poorly controlled asthma. 


\section{KEY REFERENCES}

Papers of special note have been highlighted as:

- of interest

• of considerable interest

1. Adams N, Bestall J, Jones P, Lasserson T, Griffiths B, Cates C. Fluticasone at different doses for chronic asthma in adults and children. Cochrane Database of Systematic Reviews, Issue 4. Art. No.: CD003534. DOI: 10.1002/14651858.CD003534.pub3 (2008).

2. Bateman ED, Boushey HA, Bousquet J et al. Can Guideline-defined Asthma Control Be Achieved?: The Gaining Optimal Asthma ControL Study. Am. J. Respir. Crit. Care Med., 170(8), 836-844 (2004).

3. Travers J, Marsh S, Williams M et al. External validity of randomised controlled trials in asthma: to whom do the results of the trials apply? Thorax, 62(3), 219-223 (2007).

4. Malmstrom K, Rodriguez-Gomez G, Guerra J et al. Oral Montelukast, Inhaled Beclomethasone, and Placebo for Chronic Asthma: A Randomized, Controlled Trial. Ann Intern Med, 130(6), 487-495 (1999).

5. Colice GL, Stampone P, Leung DYM, Szefler SJ. Oral corticosteroids in poorly controlled asthma. J Allergy Clin Immunol, 115(1), 200-201 (2005).

6. Szefler SJ, Martin RJ. Lessons learned from variation in response to therapy in clinical trials. J Allergy Clin Immunol, 125(2), 285-292 (2010).

7. Lipworth BJ. Systemic adverse effects of inhaled corticosteroid therapy: A systematic review and meta-analysis. Arch Intern Med, 159(9), 941-955 (1999). 
8. Lapi F, Kezouh A, Suissa S, Ernst P. The use of inhaled corticosteroids and the risk of adrenal insufficiency. Eur Respir J, 42(1), 79-86 (2013).

9. Ernst P, Suissa S. Systemic effects of inhaled corticosteroids. Curr Opin Pulm Med, 18(1), 85-89. (2012).

10. Clemmer GL, Wu AC, Rosner B et al. Measuring the corticosteroid responsiveness endophenotype in asthmatic patients. J Allergy Clin Immunol, 136(2), 274-281 (2015).

** A composite phenotype that includes information on inhaled corticosteroid treatment response in patients with mild to moderate asthma assessed by six outcomes (lung function, bronchodilator response, airway responsiveness, symptoms, need for oral corticosteroids and frequency of emergency department visits and hospitalizations) is reported to identify endophenotypes that more accurately describe corticosteroid sensitivity and insensitivity

11. Woodruff PG, Modrek B, Choy DF et al. T-helper Type 2-driven Inflammation Defines Major Subphenotypes of Asthma. Am. J. Respir. Crit. Care Med., 180(5), 388-395 (2009).

12. Cowan DC, Taylor DR, Peterson LE et al. Biomarker-based asthma phenotypes of corticosteroid response. J Allergy Clin Immunol, 135, 877-883 (2015 ).

13. Kelly MM, King EM, Rider CF et al. Corticosteroid-induced gene expression in allergenchallenged asthmatic subjects taking inhaled budesonide. Br J Pharmacol, 165(6), 1737-1747 (2012).

14. van der Schee MP, Palmay R, Cowan JO, Taylor DR. Predicting steroid responsiveness in patients with asthma using exhaled breath profiling. Clin Exp Allergy, 43(11), 12171225 (2013). 
15. Livingston E, Chaudhuri R, McMahon AD, Fraser I, McSharry CP, Thomson NC.

Systemic sensitivity to corticosteroids in smokers with asthma. Eur Respir J, 29(1), 64-

71 (2007).

16. Maranville JC, Baxter SS, Torres JM, Di Rienzo A. Inter-ethnic differences in lymphocyte sensitivity to glucocorticoids reflect variation in transcriptional response. Pharmacogenomics 13(2), 121-129 (2013).

17. Chun E, Lee H-S, Bang B-R et al. Dexamethasone-Induced FKBP51 Expression in Peripheral Blood Mononuclear Cells Could Play a Role in Predicting the Response of Asthmatics to Treatment with Corticosteroids. J Clin Immunol, 31(1), 122-127 (2011).

18. Goleva E, Jackson LP, Gleason M, Leung DYM. Usefulness of PBMCs to predict clinical response to corticosteroids in asthmatic patients. J Allergy Clin Immunol, 129(3), 687693 (2012).

19. The Childhood Asthma Management Program Research G. Long-Term Effects of Budesonide or Nedocromil in Children with Asthma. N Engl J Med, 343(15), 1054-1063 (2000).

20. Tantisira KG, Hwang ES, Raby BA et al. TBX21: A functional variant predicts improvement in asthma with the use of inhaled corticosteroids. Proc Natl Acad Sci, 101(52), 18099-18104 (2004).

21. Tantisira K, Lake S, Silverman E et al. Corticosteroid pharmacogenetics: association of sequence variants in CRHR1 with improved lung function in asthmatics treated with inhaled corticosteroids. Hum Mol Genet, 13, 1353-1359 (2004).

22. Tantisira KG, Silverman ES, Mariani TJ et al. FCER2: A pharmacogenetic basis for severe exacerbations in children with asthma. J Allergy Clin Immunol, 120(6), 1285-1291 (2007). 
23. Tantisira KG, Lasky-Su J, Harada M et al. Genomewide Association between GLCCI1 and Response to Glucocorticoid Therapy in Asthma. N Eng J Med, 365(13), 1173-1183 (2011).

24. Tantisira KG, Damask A, Szefler SJ et al. Genome-wide Association Identifies the T Gene as a Novel Asthma Pharmacogenetic Locus. Am J Respir Crit Care Med, 185(12), 1286-1291 (2012).

25. Wang $\mathrm{Y}$, Tong $\mathrm{C}$, Wang Z et al. Pharmacodynamic genome-wide association study identifies new responsive loci for glucocorticoid intervention in asthma.

Pharmacogenomics J, 15(5), 422-429 (2015).

26. Sharma S, Kho AT, Chhabra D et al. Glucocorticoid Genes and the Developmental Origins of Asthma Susceptibility and Treatment Response. Am J Respir Cell Mol Biol, 52(5), 543-553 (2015).

27. Chalmers GW, Macleod KJ, Little SA, Thomson L, McSharry CP, Thomson NC. Influence of cigarette smoking on inhaled corticosteroid treatment in mild asthma. Thorax, 57(3), 226-230 (2002).

28. Lazarus SC, Chinchilli VM, Rollings NJ et al. Smoking Affects Response to Inhaled Corticosteroids or Leukotriene Receptor Antagonists in Asthma. Am. J. Respir. Crit. Care Med., 175(8), 783-790 (2007).

29. Chaudhuri R, Livingston E, McMahon AD, Thomson L, Borland W, Thomson NC. Cigarette smoking impairs the therapeutic response to oral corticosteroids in chronic asthma. Am J Respir Crit Care Med, 168(11), 1308-1311 (2003).

30. Polosa R, Thomson NC. Smoking and asthma: dangerous liaisons. Eur Respir J, 41(3), 716-726 (2013). 
** Provides an overview of recent evidence on the harmful effects of smoking in asthma, possible underlying inflammatory mechanisms for this altered response, management options for these patients and potential future therapeutic directions.

31. Tomlinson JEM, McMahon AD, Chaudhuri R, Thompson JM, Wood SF, Thomson NC. Efficacy of low and high dose inhaled corticosteroid in smokers versus non-smokers with mild asthma. Thorax, 60(4), 282-287 (2005).

32. Telenga $\mathrm{E}$, Kerstjens $\mathrm{H}$, ten Hacken $\mathrm{N}$, Postma $\mathrm{D}$, van den Berge M. Inflammation and corticosteroid responsiveness in ex-, current- and never-smoking asthmatics. BMC Pulm Med, 13(1), 58 (2013).

33. Dijkstra A, Vonk JM, Jongepier $\mathrm{H}$ et al. Lung function decline in asthma: association with inhaled corticosteroids, smoking and sex. Thorax, 61(2), 105-110 (2006).

34. Lange $P$, Scharling $H$, Ulrik CS, Vestbo J. Inhaled corticosteroids and decline of lung function in community residents with asthma. Thorax, 61(2), 100-104 (2006).

35. O'Byrne PM, Lamm CJ, Busse WW, Tan WC, Pedersen Sr. The Effects of Inhaled Budesonide on Lung Function in Smokers and Nonsmokers With Mild Persistent Asthma. Chest, 136(6), 1514-1520 (2009).

36. Cohen RT, Raby BA, Van Steen $\mathrm{K}$ et al. In utero smoke exposure and impaired response to inhaled corticosteroids in children with asthma. J Allergy Clin Immunol, 126(3), 491497 (2010).

37. Nimmagadda S, Szefler S, Spahn J, Surs W, Leung D. Allergen exposure decreases glucocorticoid receptor binding affinity and steroid responsiveness in atopic asthmatics. Am J Respir Crit Care Med, 155, 87-93 (1997). 
38. Larsson S, Hansson L, Greiff L et al. Natural allergen exposure does not diminish the sensitivity of cytokine production to glucocorticoids in blood cells of seasonal allergic asthma and rhinitis patients. Resp Med, 96, 927-933 (2002).

39. Castanhinha S, Sherburn R, Walker S et al. Pediatric severe asthma with fungal sensitization is mediated by steroid-resistant IL-33. J Allergy Clin Immunol, 136(2), 312-322 (2015).

40. Li L-b, Goleva E, Hall CF, Ou L-S, Leung DYM. Superantigen-induced corticosteroid resistance of human T cells occurs through activation of the mitogen-activated protein kinase kinase/extracellular signal-regulated kinase (MEK-ERK) pathway. J Allergy Clin Immunol, 114(5), 1059-1069 (2004).

41. Fakhri S, Tulic M, Christodoulopoulos P et al. Microbial superantigens induce glucocorticoid receptor beta and steroid resistance in a nasal explant model. Laryngoscope, 114, 887-892 (2004).

42. Goleva E, Jackson LP, Harris JK et al. The Effects of Airway Microbiome on Corticosteroid Responsiveness in Asthma. Am J Respir Crit Care Med, 188(10), 11931201 (2013).

43. Goleva E, Hauk PJ, Hall CF et al. Corticosteroid-resistant asthma is associated with classical antimicrobial activation of airway macrophages. J Allergy Clin Immunol, 122(3), 550-559. (2008).

44. Hadebe S, Kirstein F, Fierens K et al. Microbial Ligand Costimulation Drives Neutrophilic Steroid-Refractory Asthma. PLoS ONE, 10(8), e0134219 (2015).

45. Ducharme FM, Lemire C, Noya FJD et al. Preemptive Use of High-Dose Fluticasone for Virus-Induced Wheezing in Young Children. N Eng J Med, 360(4), 339-353 (2009). 
46. Papi A, Contoli M, Adcock IM et al. Rhinovirus infection causes steroid resistance in airway epithelium through nuclear factor $\mathrm{kB}$ and c-Jun N-terminal kinase activation. J Allergy Clin Immunol, 132(5), 1075-1085 (2013).

47. Footitt J, Mallia P, Durham AL et al. Oxidative and nitrosative stress and histone deacetylase- 2 activity in exacerbations of chronic obstructive pulmonary disease. Chest, doi: 10.1378/chest.14-2637. [Epub ahead of print (2015).

48. McSharry C, Spears M, Chaudhuri R, Cameron EJ, Husi H, Thomson NC. Increased sputum endotoxin levels are associated with an impaired lung function response to oral steroids in asthmatic patients. J Allergy Clin Immunol, 134(5), 1068-1075 (2014).

* Increased sputum endotoxin concentrations are associated with an impaired lung function response to oral corticosteroids, particularly in never smokers with asthma, which suggests that airway endotoxin may contribute to corticosteroid insensitivity in asthma

49. Sutherland ER, Goleva E, Jackson LP, Stevens AD, Leung DYM. Vitamin D Levels, Lung Function, and Steroid Response in Adult Asthma. Am. J. Respir. Crit. Care Med., 181(7), 699-704 (2010).

50. Pavord I, Brightling C, Woltmann G, Wardlaw A. Non-eosinophilic corticosteroid unresponsive asthma. Lancet, 353, 2213-2214 (1999).

51. McGrath KW, Icitovic N, Boushey HA et al. A Large Subgroup of Mild-to-Moderate Asthma Is Persistently Noneosinophilic. Am J Respir Crit Care Med, 185(6), 612-619 (2012).

52. Chung EH, Jia Y, Ohnishi H et al. LeukotrieneB4 receptor 1 is Differentially Expressed on Peripheral T Cells of Steroid-Sensitive and -Resistant Asthmatics. Ann Allergy Asthma Immunol, 112(3), 211-216.e211 (2014). 
53. Bourdin A, Kleis S, Chakra M et al. Limited Short-term Steroid Responsiveness Is Associated With Thickening of Bronchial Basement Membrane in Severe Asthma. Chest, 141(6), 1504-1511 (2012).

54. Heaney LG, Horne R. Non-adherence in difficult asthma: time to take it seriously. Thorax, 67(3), 268-270 (2012).

55. Williams LK, Peterson EL, Wells K et al. Quantifying the proportion of severe asthma exacerbations attributable to inhaled corticosteroid nonadherence. J Allergy Clin Immunol, 128(6), 1185-1191. (2011).

56. Gamble J, Stevenson M, McClean E, Heaney LG. The Prevalence of Nonadherence in Difficult Asthma. Am J Respir Crit Care Med, 180(9), 817-822 (2009).

57. Haczku A, Panettieri Jr RA. Social stress and asthma: The role of corticosteroid insensitivity. J Allergy Clin Immunol, 125(3), 550-558 (2010).

58. Federico MJ, Covar RA, Brown EE, Leung DYM, Spahn JD. Racial Differences in TLymphocyte Response to Glucocorticoids. Chest, 127(2), 571-578 (2005).

59. Dunn RM, Lehman E, Chinchilli VM et al. Impact of Age and Gender on Response to Asthma Therapy. Am J Resp Crit Care Med, 192, 551-558 (2015 ).

* In Asthma Clinical Research Network (ACRN) trials in non-smokers with mild to moderate asthma, treatment failures (worsening asthma resulting in systemic corticosteroid use, hospitalization, emergency department visit, prolonged decrease in $\mathrm{PEF}$, increase in albuterol use, or safety concerns including exacerbations) increased for every year above age 30 years in participants receiving inhaled corticosteroids.

60. Wechsler ME, Castro M, Lehman E et al. Impact of Race on Asthma Treatment Failures in the Asthma Clinical Research Network. Am J Resp Crit Care Med, 184(11), 12471253 (2011). 
61. Gould W, Peterson EL, Karungi G et al. Factors predicting inhaled corticosteroid responsiveness in African American patients with asthma. J Allergy Clin Immunol, 126(6), 1131-1138 (2010).

62. Boulet L-P, Franssen E. Influence of obesity on response to fluticasone with or without salmeterol in moderate asthma. Respir Med, 101(11), 2240-2247 (2007).

63. Sutherland ER, Lehman EB, Teodorescu M, Wechsler ME. Body mass index and phenotype in subjects with mild-to-moderate persistent asthma. J Allergy Clin Immunol, 123(6), 1328-1334 (2009).

64. Sutherland ER, Goleva E, Strand M, Beuther DA, Leung DYM. Body Mass and Glucocorticoid Response in Asthma. Am J Respir Crit Care Med, 178(7), 682-687 (2008).

65. Fingleton J, Travers J, Williams M et al. Treatment responsiveness of phenotypes of symptomatic airways obstruction in adults. J Allergy Clin Immunol, 136(3), 601-609 (2015).

66. Invernizzi G, Ruprecht A, De Marco C, Mazza R, Nicolini G, Boffi R. Inhaled steroid/tobacco smoke particle interactions: a new light on steroid resistance. Resp Res, 10(1), 48 (2009).

67. Lane S, Palmer JBD, Skidmore IF, Lee T. Corticosteroid pharmacokinetics in asthma. Lancet, 336(8725), 1265 (1990).

68. Barnes PJ. Glucocorticosteroids: current and future directions. Br J Pharmol, 163(1), 29-43 (2011).

* Comprehensive review of the mode of action of corticosteroids in asthma and COPD 
69. Clark AR, Belvisi MG. Maps and legends: The quest for dissociated ligands of the glucocorticoid receptor. Pharmacol \& Ther, 134(1), 54-67 (2012).

70. Boardman C, Chachi L, Gavrila A et al. Mechanisms of glucocorticoid action and insensitivity in airways disease. Pulm Pharmacol Therap, 29(2), 129-143 (2014).

71. Barnes PJ. Corticosteroid resistance in patients with asthma and chronic obstructive pulmonary disease. J Allergy Clin Immunol, 131(3), 636-645 (2013).

** Comprehensive review of the mechanisms of corticosteroid resistance in asthma and COPD

72. Keenan CR, Radojicic D, Li M, Radwan A, Stewart AG. Heterogeneity in mechanisms influencing glucocorticoid sensitivity: The need for a systems biology approach to treatment of glucocorticoid-resistant inflammation. Pharmacol Ther, 150, 81-93 (2015).

73. Vazquez-Tello A, Semlali A, Chakir J et al. Induction of glucocorticoid receptor-B2; expression in epithelial cells of asthmatic airways by T-helper type 17 cytokines. Clin Exp Allergy, 40(9), 1312-1322 (2010).

74. Livingston E, Darroch C, Chaudhuri R et al. Glucocorticoid receptor alpha to beta ratio in blood mononuclear cells is reduced in cigarette smokers. J Allergy Clin Immunol, $114,1475-1478$ (2004).

75. Goleva E, Li L-b, Eves PT, Strand MJ, Martin RJ, Leung DYM. Increased Glucocorticoid Receptor beta Alters Steroid Response in Glucocorticoid-insensitive Asthma. Am. J. Respir. Crit. Care Med., 173(6), 607-616 (2006).

76. Butler CA, McQuaid S, Taggart CC et al. Glucocorticoid receptor $\beta$ and histone deacetylase 1 and 2 expression in the airways of severe asthma. Thorax, 67(5), 392398 (2012). 
77. Sutherland ER, Goleva E, King TS et al. Cluster Analysis of Obesity and Asthma Phenotypes. PLoS ONE, 7(5), e36631 (2012).

78. Kobayashi Y, Mercado N, Barnes PJ, Ito K. Defects of Protein Phosphatase 2A Causes Corticosteroid Insensitivity in Severe Asthma. PLoS ONE, 6(12), e27627 (2011).

79. Bhavsar P, Hew M, Khorasani N et al. Relative corticosteroid insensitivity of alveolar macrophages in severe asthma compared with non-severe asthma. Thorax, 63(9), 784-790 (2008).

80. Li JJ, Wang W, Baines KJ et al. IL-27/IFN-gamma Induce MyD88-Dependent SteroidResistant Airway Hyperresponsiveness by Inhibiting Glucocorticoid Signaling in Macrophages. J Immunol, 185(7), 4401-4409 (2010).

81. Li JJ, Tay HL, Maltby S et al. MicroRNA-9 regulates steroid-resistant airway hyperresponsiveness by reducing protein phosphatase $2 \mathrm{~A}$ activity. J Allergy Clin Immunol, 136(2), 462-473 (2015).

82. Cornejo S, Tantisira K, Raby BA, Weiss ST, Kaplan F. Nuclear Bioavailability of the Glucocorticoid Receptor in a Pediatric Asthma Cohort with Variable Corticosteroid Responsiveness. Pediatr Res, doi: 10.1038/pr.2015.148. [Epub ahead of print] (2015 ).

83. Hakonarson H, Bjornsdottir US, Halapi E et al. Profiling of genes expressed in peripheral blood mononuclear cells predicts glucocorticoid sensitivity in asthma patients. PNAS, 102(41), 14789-14794 (2005).

84. Loke T-K, Mallett KH, Ratoff J et al. Systemic glucocorticoid reduces bronchial mucosal activation of activator protein 1 components in glucocorticoid-sensitive but not glucocorticoid-resistant asthmatic patients. J Allergy Clin Immunol, 118(2), 368-375 (2006). 
85. Ito K, Caramori G, Lim S et al. Expression and activity of histone deacetylases in human asthmatic airways. Am J Respir Crit Care Med, 166(3), 392-396 (2002).

86. Hew M, Bhavsar P, Torrego A et al. Relative Corticosteroid Insensitivity of Peripheral Blood Mononuclear Cells in Severe Asthma. Am. J. Respir. Crit. Care Med., 174(2), 134141 (2006).

87. Cosio BG, Mann B, Ito K et al. Histone Acetylase and Deacetylase Activity in Alveolar Macrophages and Blood Mononocytes in Asthma. Am. J. Respir. Crit. Care Med., 170(2), 141-147 (2004).

88. Ito K, Lim S, Caramori G, Chung K, Barnes P, Adcock I. Cigarette smoking reduces histone deacetylase 2 expression, enhances cytokine expression, and inhibits glucocorticoid actions in alveolar macrophages. FASEB J, 15(6), 1110-1112 (2001).

89. Cosio BG, Tsaprouni L, Ito K, Jazrawi E, Adcock IM, Barnes PJ. Theophylline Restores Histone Deacetylase Activity and Steroid Responses in COPD Macrophages. J. Exp. Med., 200, 689-695 (2004).

90. Hawrylowicz C, Richards D, Loke T-K, Christopher Corrigan C, Lee T. A defect in corticosteroid-induced IL-10 production in T lymphocytes from corticosteroid-resistant patients. J Allergy Clin Immunol, 109(2), 369-370 (2002).

91. Dejager L, Dendoncker K, Eggermont M et al. Neutralizing TNF[alpha] restores glucocorticoid sensitivity in a mouse model of neutrophilic airway inflammation. Mucosal Immunol, doi: 10.1038/mi.2015.12. [Epub ahead of print] (2015).

92. Bel EH, Sousa A, Fleming L et al. Diagnosis and definition of severe refractory asthma: an international consensus statement from the Innovative Medicine Initiative (IMI). Thorax, 66(10), 910-917 (2011). 
93. Schlender A, Alperin PE, Grossman HL, Sutherland ER. Modeling the Impact of Increased Adherence to Asthma Therapy. PLoS ONE, 7(12), e51139 (2012).

94. Chaudhuri R, Livingston E, McMahon AD et al. Effects of Smoking Cessation on Lung Function and Airway Inflammation in Smokers with Asthma. Am. J. Respir. Crit. Care Med., 174(2), 127-133 (2006).

95. British guideline on the management of asthma. (Eds) (2014) 1-180.

96. Zhang Y, Leung DYM, Goleva E. Anti-inflammatory and corticosteroid-enhancing actions of vitamin D in monocytes of patients with steroid-resistant and those with steroid-sensitive asthma. J Allergy Clin Immunol, 133(6), 1744-1752. (2014).

97. Nanzer AM, Chambers ES, Ryanna K et al. Enhanced production of IL-17A in patients with severe asthma is inhibited by $1 \hat{I} \pm, 25$-dihydroxyvitamin D3 in a glucocorticoidindependent fashion. J Allergy Clin Immunol, 132(2), 297-304. (2013).

* Vitamin D3 supplementation in patients with corticosteroid resistant asthma demonstrated an increase in dexamethasone-induced IL-10 production in vitro as well as suppression of dexamethasone-induced IL-17A production

98. Xystrakis E, Kusumakar S, Boswell S et al. Reversing the defective induction of IL-10secreting regulatory T cells in glucocorticoid-resistant asthma patients. J Clin Invest, 116(1), 146-155 (2006).

99. Nanzer AM, Chambers ES, Ryanna K et al. The effects of calcitriol treatment in glucocorticoid-resistant asthma. J Allergy Clin Immunol, 133(6), 1755-1757. (2014).

100. Chambers ES, Nanzer AM, Pfeffer PE et al. Distinct endotypes of steroid-resistant asthma characterized by IL-17Ahigh and IFN-phigh immunophenotypes: Potential benefits of calcitriol. J Allergy Clin Immunol, 136(3), 628-637 (2015). 
101. Castro M, King TS, Kunselman SJ et al. Effect of vitamin D3 on asthma treatment failures in adults with symptomatic asthma and lower vitamin d levels: The VIDA randomized clinical trial. JAMA, 311(20):2083-91(20), 2083-2091 (2014).

102. Martineau AR, Hanifa Y, Witt KD et al. Double-blind randomised controlled trial of vitamin D3 supplementation for the prevention of acute respiratory infection in older adults and their carers (ViDiFlu). Thorax, 70(10), 953-960 (2015).

103. de Groot JC, van Roon ENH, Storm H et al. Vitamin D reduces eosinophilic airway inflammation in nonatopic asthma. J Allergy Clin Immunol, 135(3), 670-675.e673 (2015).

104. Roche N, Postma DS, Colice G et al. Differential Effects of Inhaled Corticosteroids in Smokers/Ex-Smokers and Nonsmokers with Asthma. Am J Resp Crit Care Med, 191(8), 960-964 (2015).

105. Kobayashi Y, Mercado N, Miller-Larsson A, Barnes PJ, Ito K. Increased corticosteroid sensitivity by a long acting $\beta 2$ agonist formoterol via $\beta 2$ adrenoceptor independent protein phosphatase 2A activation. Pulm Pharm Therap, 25(3), 201-207 (2012).

106. Rossios C, To Y, Osoata G, Ito M, Barnes PJ, Ito K. Corticosteroid insensitivity is reversed by formoterol via phosphoinositide-3-kinase inhibition. Br J Pharmacol, 167(4), 775-786 (2012).

107. Manetsch M, Ramsay EE, King EM et al. Corticosteroids and $\beta 2$-agonists upregulate mitogen-activated protein kinase phosphatase 1: in vitro mechanisms. Br J Pharmacol, 166(7), 2049-2059 (2012).

108. To Y, Ito K, Kizawa Y et al. Targeting phosphoinositide-3-kinase-delta with theophylline reverses corticosteroid insensitivity in chronic obstructive pulmonary disease. Am J Respir Crit Care Med, 182(7), 897-904 (2010). 
109. Spears M, Donnelly I, Jolly L et al. Effect of low-dose theophylline plus

beclometasone on lung function in smokers with asthma: a pilot study. Eur Respir J, 33(5), 1010-1017 (2009).

* An exploratory study examined the impact of low dose theophylline added to inhaled corticosteroid compared to inhaled corticosteroid alone in a group of smokers with asthma. The addition of theophylline to inhaled corticosteroid, at a dose titrated to provide a 'sub-therapeutic' concentration, resulted in increased efficacy as measured by lung function and suggested the restoration of corticosteroid sensitivity in those treated with the combination.

110. Price D, Popov TA, Bjermer L et al. Effect of montelukast for treatment of asthma in cigarette smokers. J Allergy Clin Immunol, 131(3), 763-771 (2013).

111. Normansell R, Walker S, Milan SJ, Walters EH, Nair P. Omalizumab for asthma in adults and children. Cochrane Database of Systematic Reviews, Issue 1. Art. No.: CD003559. DOI:10.1002/14651858.CD003559.pub4. (2014).

112. Ortega HG, Liu MC, Pavord ID et al. Mepolizumab Treatment in Patients with Severe Eosinophilic Asthma. N Eng J Med, 371(13), 1198-1207 (2014).

113. Bel EH, Wenzel SE, Thompson PJ et al. Oral Glucocorticoid-Sparing Effect of Mepolizumab in Eosinophilic Asthma. N Eng J Med, 371(13), 1189-1197 (2014).

114. Cameron EJ, McSharry C, Chaudhuri R, Farrow S, Thomson NC. Long-term macrolide treatment of chronic inflammatory airway diseases: risks, benefits and future developments. Clin Exp Allergy, 42(9), 1302-1312 (2012).

115. Kobayashi Y, Wada H, Rossios C et al. A Novel Macrolide Solithromycin Exerts Superior Anti-inflammatory Effect via NF-kB Inhibition. J Pharmacol Exp Ther, 345(1), 76-84 (2013). 
116. Kobayashi Y, Wada H, Rossios C et al. A novel macrolide/fluoroketolide, solithromycin (CEM-101), reverses corticosteroid insensitivity via phosphoinositide 3kinase pathway inhibition. Br J Pharmacol, 169(5), 1024-1034 (2013).

117. Essilfie A-T, Horvat JC, Kim RY et al. Macrolide therapy suppresses key features of experimental steroid-sensitive and steroid-insensitive asthma. Thorax, 70(5), 458-467 (2015).

118. Cameron EJ, Chaudhuri R, Mair F et al. Randomised controlled trial of azithromycin in smokers with asthma. Eur Respir J, 42(5), 1412-1415 (2013).

119. Brusselle GG, VanderStichele C, Jordens P et al. Azithromycin for prevention of exacerbations in severe asthma (AZISAST): a multicentre randomised double-blind placebo-controlled trial. Thorax, 68(4), 322-329 (2013).

120. Balloy V, Deveaux A, Lebeaux D et al. Azithromycin analogue CSY0073 attenuates lung inflammation induced by LPS challenge. Br J Pharmacol, 171(7), 1783-1794 (2014).

121. Bhavsar P, Khorasani N, Hew M, Johnson M, Chung KF. Effect of p38 MAPK inhibition on corticosteroid suppression of cytokine release in severe asthma. Eur Respir J, 35(4), 750-756 (2010).

122. Guntur VP, Reinero CR. The potential use of tyrosine kinase inhibitors in severe asthma. Curr Opin Allergy Clin Immunol, 12(1), 68-75 (2012).

123. Chung KF. p38 Mitogen-Activated Protein Kinase Pathways in Asthma and COPD. Chest, 139(6), 1470-1479 (2011).

124. Mercado N, Hakim A, Kobayashi Y et al. Restoration of Corticosteroid Sensitivity by p38 Mitogen Activated Protein Kinase Inhibition in Peripheral Blood Mononuclear Cells from Severe Asthma. PLoS ONE, 7(7), e41582 (2012). 
125. Khorasani N, Baker J, Johnson M, Chung KF, Bhavsar PK. Reversal of corticosteroid insensitivity by p38 MAPK inhibition in peripheral blood mononuclear cells from COPD. Int J Chron Obstruct Pulmon Dis, 10, 283-291 (2015).

126. Rhee CK, Kim JW, Park CK et al. Effect of Imatinib on Airway Smooth Muscle Thickening in a Murine Model of Chronic Asthma. Int Arch Allergy Immunol, 155(3), 243-251 (2011).

127. Humbert M, De Blay F, Garcia G et al. Masitinib, a c-kit/PDGF receptor tyrosine kinase inhibitor, improves disease control in severe corticosteroid-dependent asthmatics. Allergy, 64(8), 1194-1201 (2009).

128. Marwick JA, Caramori G, Casolari P et al. A role for phosphoinositol 3-kinase delta in the impairment of glucocorticoid responsiveness in patients with chronic obstructive pulmonary disease. J Allergy Clin Immunol, 125(5), 1146-1153 (2010).

129. Ito K, Caramori G, Adcock IM. Therapeutic Potential of Phosphatidylinositol 3-Kinase Inhibitors in Inflammatory Respiratory Disease. J Pharmacol Exp Ther, 321(1), 1-8 (2007).

130. Doukas J, Eide L, Stebbins K et al. Aerosolized Phosphoinositide 3-Kinase \{gamma\}/\{delta\} Inhibitor TG100-115 [3-[2,4-Diamino-6-(3-hydroxyphenyl)pteridin-7yl]phenol] as a Therapeutic Candidate for Asthma and Chronic Obstructive Pulmonary Disease. J Pharmacol Exp Ther, 328(3), 758-765 (2009).

131. Mercado N, To Y, Kobayashi Y, Adcock IM, Barnes PJ, Ito K. p38 Mitogen-Activated Protein Kinase- $\hat{I}^{3}$ Inhibition by Long-Acting $\hat{I}^{2} 2$ Adrenergic Agonists Reversed Steroid Insensitivity in Severe Asthma. Mol Pharmacol, 80(6), 1128-1135 (2011).

132. Schuliga M. NF-kappaB Signaling in Chronic Inflammatory Airway Disease. Biomolecules, 5(3), 1266 (2015). 
133. Page CP, Spina D. Selective PDE inhibitors as novel treatments for respiratory diseases. Curr Opin Pharmacol, 12(3), 275-286 (2012).

* Comprehensive review of selective PDE inhibitors as novel treatments for respiratory diseases.

134. Milara J, Lluch J, Almudever P, Freire J, Xiaozhong Q, Cortijo J. Roflumilast N-oxide reverses corticosteroid resistance in neutrophils from patients with chronic obstructive pulmonary disease. J Allergy Clin Immunol, 134(2), 314-322.e319 (2014).

135. Chapman RW, House A, Richard J et al. Pharmacology of a potent and selective inhibitor of PDE4 for inhaled administration. Eur J Pharmacol, 643(2-3), 274-281 (2010).

136. Singh D, Petavy F, Macdonald A, Lazaar A, O'Connor B. The inhaled phosphodiesterase 4 inhibitor GSK256066 reduces allergen challenge responses in asthma. Resp Res, 11(1), 26 (2010).

137. Moretto N, Caruso P, Bosco R et al. CHF6001, a novel highly potent and selective phosphodiesterase 4 inhibitor with robust anti-inflammatory activity and suitable for topical pulmonary administration. J Pharmacol Exp Ther, 352(3), 559-567. (2015).

138. Watz H, Mistry S, Lazaar A, investigators. I. Safety and tolerability of the inhaled phosphodiesterase 4 inhibitor GSK256066 in moderate COPD. Pulm Pharmacol Ther, 26(5), 588-595 (2013).

139. Milara J, Navarro A, Almudéver P, Lluch J, Morcillo EJ, Cortijo J. Oxidative stressinduced glucocorticoid resistance is prevented by dual PDE3/PDE4 inhibition in human alveolar macrophages. Clin Exp Allergy, 41(4), 535-546 (2011).

140. Franciosi LG, Diamant Z, Banner KH et al. Efficacy and safety of RPL554, a dual PDE3 and PDE4 inhibitor, in healthy volunteers and in patients with asthma or chronic 
obstructive pulmonary disease: findings from four clinical trials. Lancet Respir Med, 1(9), 714-727 (2013).

141. Spears M, McSharry C, Thomson NC. Peroxisome proliferator-activated receptorgamma agonists as potential anti-inflammatory agents in asthma and chronic obstructive pulmonary disease. Clin Exp Allergy, 36(12), 1494-1504 (2006).

142. Lea S, Plumb J, Metcalfe $\mathrm{H}$ et al. The effect of peroxisome proliferator-activated receptor- $\gamma$ ligands on in vitro and in vivo models of COPD. Eur Respir J, 43(2), 409-420 (2014).

143. Spears M, Donnelly I, Jolly L et al. Bronchodilatory Effect of the PPAR-[gamma] Agonist Rosiglitazone in Smokers With Asthma. Clin Pharmacol Ther, 86(1), 49-53 (2009).

144. Hothersall E, McSharry C, Thomson NC. Potential therapeutic role for statins in respiratory disease. Thorax, 61(8), 729-734 (2006).

145. Yeganeh B, Wiechec E, Ande S et al. Targeting the mevalonate cascade as a new therapeutic approach in heart disease, cancer and pulmonary disease. Pharmacol Ther, 143(1), 87-110 (2014).

146. McKay A, Leung BP, McInnes IB, Thomson NC, Liew FY. A Novel Anti-Inflammatory Role of Simvastatin in a Murine Model of Allergic Asthma. J Immunol, 172(5), 29032908 (2004).

147. Lee J-H, Lee D-S, Kim E-K et al. Simvastatin Inhibits Cigarette Smoking-induced Emphysema and Pulmonary Hypertension in Rat Lungs. Am. J. Respir. Crit. Care Med., 172(8), 987-993 (2005).

148. Samson K, Minoguchi K, Tanaka A et al. Inhibitory effects of fluvastatin on cytokine and chemokine production by peripheral blood mononuclear cells in patients with allergic asthma. Clin Exp Allergy, 36(4), 475-482 (2006). 
149. Maneechotesuwan K, Ekjiratrakul W, Kasetsinsombat K, Wongkajornsilp A, Barnes

PJ. Statins enhance the anti-inflammatory effects of inhaled corticosteroids in asthmatic patients through increased induction of indoleamine 2, 3-dioxygenase. J Allergy Clin Immunol, 126(4), 754-762 (2010).

150. Braganza G, Chaudhuri R, McSharry C et al. Effects of short-term treatment with atorvastatin in smokers with asthma - a randomized controlled trial. BMC Pulm Med, 11,16 (2011).

151. Thomson NC, Charron CE, Chaudhuri R, Spears M, Ito K, McSharry C. Atorvastatin in combination with inhaled beclometasone modulates inflammatory sputum mediators in smokers with asthma. Pulm Pharmacol Ther, 31, 1-8 (2015).

* Short-term treatment with atorvastatin alone or in combination with inhaled beclometasone reduces several sputum cytokines, chemokines and growth factors concentrations unresponsive to inhaled corticosteroids alone, in smokers with asthma.

152. Maneechotesuwan K, Kasetsinsombat K, Wongkajornsilp A, Barnes PJ. Decreased indoleamine 2,3-dioxygenase activity and IL-10/IL-17A ratio in patients with COPD. Thorax, 68(4), 330-337 (2013).

153. Leaker B, Barnes P, O'Connor B. Inhibition of LPS-induced airway neutrophilic inflammation in healthy volunteers with an oral CXCR2 antagonist. Respir Res, 14(1), 137 (2013).

154. Nair P, Gaga M, Zervas E et al. Safety and efficacy of a CXCR2 antagonist in patients with severe asthma and sputum neutrophils: a randomized, placebo-controlled clinical trial. Clin Exp Allergy, 42(7), 1097-1103 (2012). 
155. Rennard SI, Dale DC, Donohue JF et al. CXCR2 Antagonist MK-7123-A Phase 2

Proof-of-Concept Trial for Chronic Obstructive Pulmonary Disease. Am J Resp Crit Care Med, 191(9), 1001-1011 (2015).

156. Chaudhuri R, Norris V, Kelly K et al. Effects of a FLAP inhibitor, GSK2190915, in asthmatics with high sputum neutrophils. Pulm Pharmacol Ther, 27(1), 62-69 (2014).

157. Chesné J, Braza F, Mahay G, Brouard S, Aronica M, Magnan A. IL-17 in Severe Asthma. Where Do We Stand? Am J Respir Crit Care Med, 190(10), 1094-1101 (2014).

158. Busse WW, Holgate S, Kerwin E et al. Randomized, Double-Blind, Placebo-controlled Study of Brodalumab, a Human Anti-L-17 Receptor Monoclonal Antibody, in Moderate to Severe Asthma. Am J Respir Crit Care Med, 188(11), 1294-1302 (2013).

159. Wenzel SE, Barnes PJ, Bleecker ER et al. A Randomized, Double-blind, Placebocontrolled Study of Tumor Necrosis Factor-alpha Blockade in Severe Persistent Asthma. Am J Respir Crit Care Med, 179(7), 549-558 (2009).

160. Holgate ST, Noonan M, Chanez P et al. Efficacy and safety of etanercept in moderateto-severe asthma: a randomised, controlled trial. Eur Respir J, 37(6), 1352-1359 (2011).

161. Jarjour NN, Erzurum SC, Bleecker ER et al. Severe Asthma. Am J Resp Crit Care Med, 185(4), 356-362 (2012).

162. The ENFUMOSA Study Group. The ENFUMOSA cross-sectional European multicentre study of the clinical phenotype of chronic severe asthma. Eur Respir J, 22(3), 470-477 (2003).

163. Shaw DE, Sousa AR, Fowler SJ et al. Clinical and inflammatory characteristics of the European U-BIOPRED adult severe asthma cohort. Eur Respir J, 46(5), 1308-1321 (2015). 
164. Heaney LG, Djukanovic R, Woodcock A et al. Research in progress: Medical Research Council United Kingdom Refractory Asthma Stratification Programme (RASPUK). Thorax, doi: 10.1136/thoraxjnl-2015-207326. [Epub ahead of print] (2015).

\section{Websites}

201 GINA Report, Global Strategy for Asthma Management and Prevention 2014 http://www.ginasthma.com Accessed $11^{\text {th }}$ October 2015.

202 British guideline on the management of asthma. A national clinical guideline. Thorax 2014: 1-180 www.sign.ac.uk Accessed 11th October 2015. 
Table 1: Factors that potentially influence the therapeutic response to corticosteroids in patients with asthma

\section{Genetic factors}

T-box expressed in T cells21 (TBX21) polymorphisms

Corticotrophin-releasing hormone receptor 1 gene (CRHR1) polymorphisms

Low-affinity IgE receptor gene (FCER2) polymorphisms

Glucocorticoid-induced transcript 1 gene $(\mathrm{GLCCl} 1)$ polymorphisms

T gene polymorphisms

chr6 rs6924808 and chr11 rs1353649 polymorphisms

\section{Environmental factors}

Active and secondhand exposure to cigarette smoke

Allergen exposure

Infections: superantigens, airway microbiome, viruses

Endotoxin

Vitamin D deficiency

\section{Asthma associated factors}

Airway inflammatory cell phenotypes and airway remodeling

Corticosteroid resistant asthma

Non-adherence and poor inhaler technique

Concomitant disease and misdiagnosis

\section{Demographic variables}

Age

Gender

Race

Body mass index

Pharmacokinetics of corticosteroids 


\title{
Table 2 Examples of potential mechanisms of corticosteroids insensitivity in asthma
}

\author{
Alteration in glucocorticoid receptor (GR) subtypes \\ Reduction in ligand-activated GR $\alpha$ subtype numbers or activity \\ Over expression of the non-functional GRß subtype
}

Defective glucocorticoid receptor binding and nuclear translocation

Reduction in GR binding affinity and nuclear translocation

Increase in proinflammatory transcription factors

Activation of pro-inflammatory transcription factors such as nuclear factor- $\kappa B(N F-\kappa B)$, activator protein-1 (AP-1) and signal transduction-activated transcription factors (STAT)

\section{Defective histone acetylation}

Reduction in histone deacetylase (HDAC) 2 activity

Other immune mechanisms

Suppression of the anti-inflammatory cytokine interleukin (IL)-10 production 
Table 3 Current management of corticosteroid insensitivity in asthma

\author{
Non-adherence \\ Employ strategies to improve adherence \\ Non-pharmacological interventions \\ Smoking cessation \\ Weight reduction ${ }^{\ddagger}$ \\ Dietary supplementation with vitamin D3 ${ }^{\ddagger}$

\section{Current pharmacological treatments}

Inhaled corticosteroids

Step-up in dose of inhaled corticosteroid

Extrafine-particle inhaled corticosteroid ${ }^{\ddagger}$

Combination of a long acting $\beta_{2}$-agonists (LABA) and an inhaled corticosteroid

Addition of low dose theophylline to an inhaled corticosteroid ${ }^{\ddagger \ddagger}$

Leukotriene-receptor antagonist ${ }^{\ddagger \ddagger}$

Oral corticosteroid sparing therapies

Biological agents e.g. omalizumab, mepolizumab

Immunosuppressive agents e.g. methotrexate

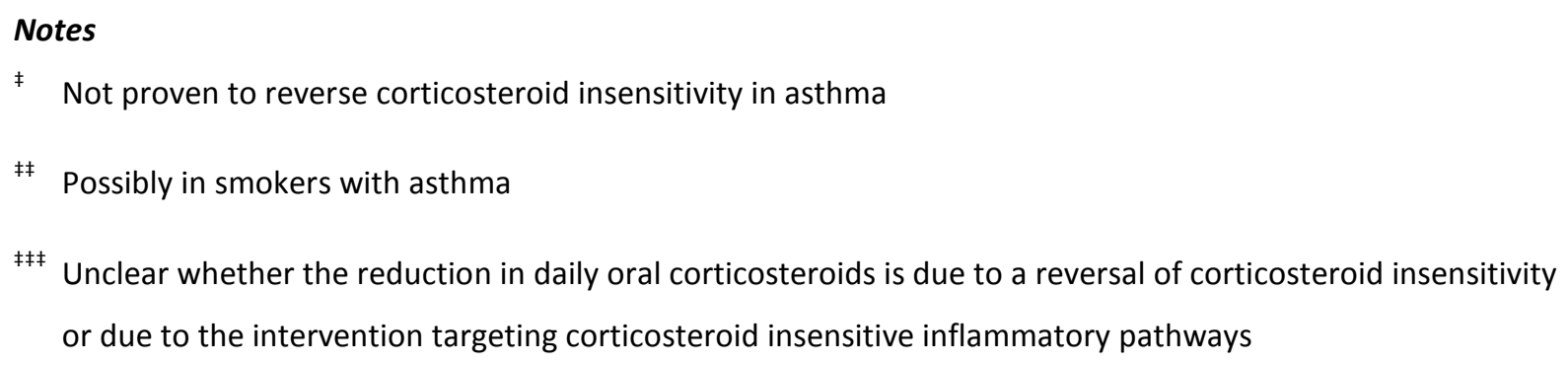


Table 4 Examples of potential future therapies for corticosteroid insensitivity

Small molecule drugs

Macrolides

Protein kinase inhibitors

p38 Mitogen-activated protein kinase (MAPK) inhibitors

Narrow spectrum kinase inhibitors

Tyrosine kinase inhibitors

Phosphinositide 3 (PI3)-kinase inhibitors

$\mathrm{PI} 3 \mathrm{~K}-\delta$ inhibitors

Dual PI3K $/ Y$ inhibitors

Nuclear factor $\kappa B(N F-\kappa B)$ inhibitors

IKB kinases (IKKS) inhibitors

Phosphodiesterase (PDE) inhibitors

$\mathrm{PDE}_{4}$ inhibitors

Dual $\mathrm{PDE}_{3}$ and $\mathrm{PDE}_{4}$ inhibitors

Peroxisome proliferator-activated receptor- $\gamma($ PPAR $\gamma)$ agonists

Statins

Drugs targeting neutrophilic inflammation

C-X-C chemokine receptor (CXCR)2 antagonists

5-lipoxygenase-activating protein (FLAP) inhibitors

Biological agents

Interleukin (IL)-17A receptor blockers

IL-17A blockers

Tumour necrosis factor (TNF)- $\alpha$ receptor blockers 


\section{FIGURE LEGENDS}

Figure 1 Variation in therapeutic response to oral corticosteroids in adults with asthma

Distribution of treatment response for change in morning peak expiratory flow (PEF) after a short course of oral corticosteroid in 784 adults with asthma. Reprinted with permission from $[5]$.

Figure 2 Association of serum endotoxin and therapeutic response to oral corticosteroids in adults with asthma

Association of percentage change in $\mathrm{FEV}_{1}$ after oral corticosteroids with sputum endotoxin concentrations in asthmatic patients. The linear regression line (solid line) with the true $95 \%$ $\mathrm{Cl}$ (dashed lines) of nonsmokers (open circles) and smokers (red squares) is shown. In the combined asthma group the percentage change in $\mathrm{FEV}_{1}$ after oral dexamethasone decreased with increasing sputum endotoxin concentration (Spearman rho: $r 520.329$ [95\% Cl, 20.570 to 20.036], $p=0.029)$. Reprinted with permission from [48].

Figure 3 Addition of low-dose theophylline to inhaled betametasone in smokers with asthma

An exploratory study examined the impact of low dose theophylline added to inhaled corticosteroid (betametasone, BDP) compared to inhaled corticosteroid (BDP) alone in a group of smokers with asthma. Change in peak expiratory flow (PEF) from randomization to 28 days of treatment. Adapted from [109].

Figure 4 Sputum mediator concentrations after atorvastatin and atorvastatin plus inhaled beclometasone or beclometasone alone in smokers with asthma

Sputum mediator concentrations after atorvastatin treatment or placebo and atorvastatin plus inhaled beclometasone or beclometasone alone in smokers with asthma. Examples of 
sputum cytokine (IL-1 $\beta$, G-CSF), chemokine (CCL7) or growth factor (FGF) concentrations after atorvastatin treatment or placebo and atorvastatin plus inhaled beclometasone or beclometasone alone.

Abbreviations: CCL: chemokine (C-C motif) ligand; FGF: Fibroblast growth factor; G-CSF: Granulocyte colony stimulating factor; IL: Interleukin; NS: not significant. Horizontal bar indicates Median (IQR). Adapted from [151]. 
Figure 1

\section{Change from Run-in After Oral} Corticosteriods

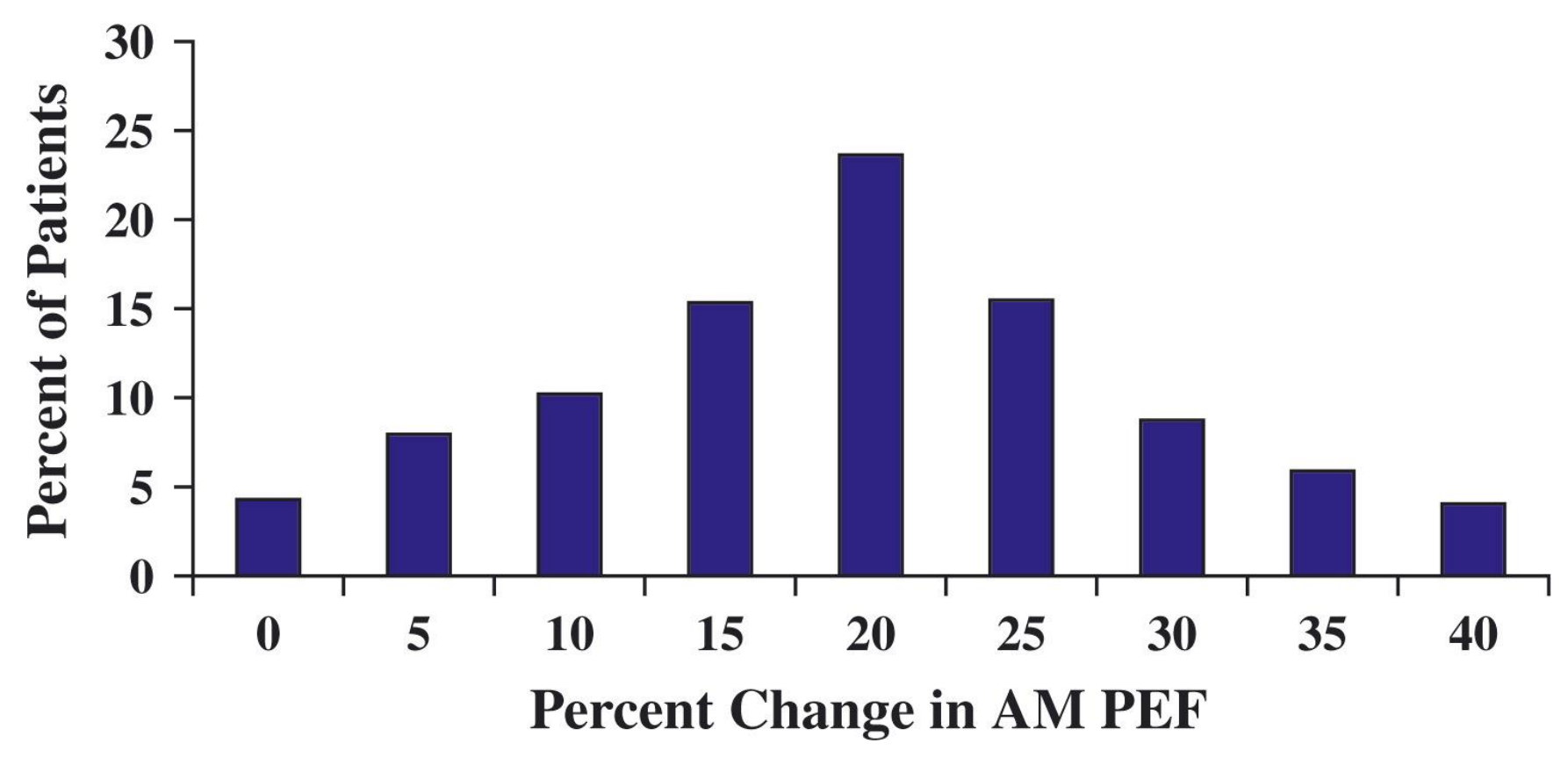




\section{Figure 2}

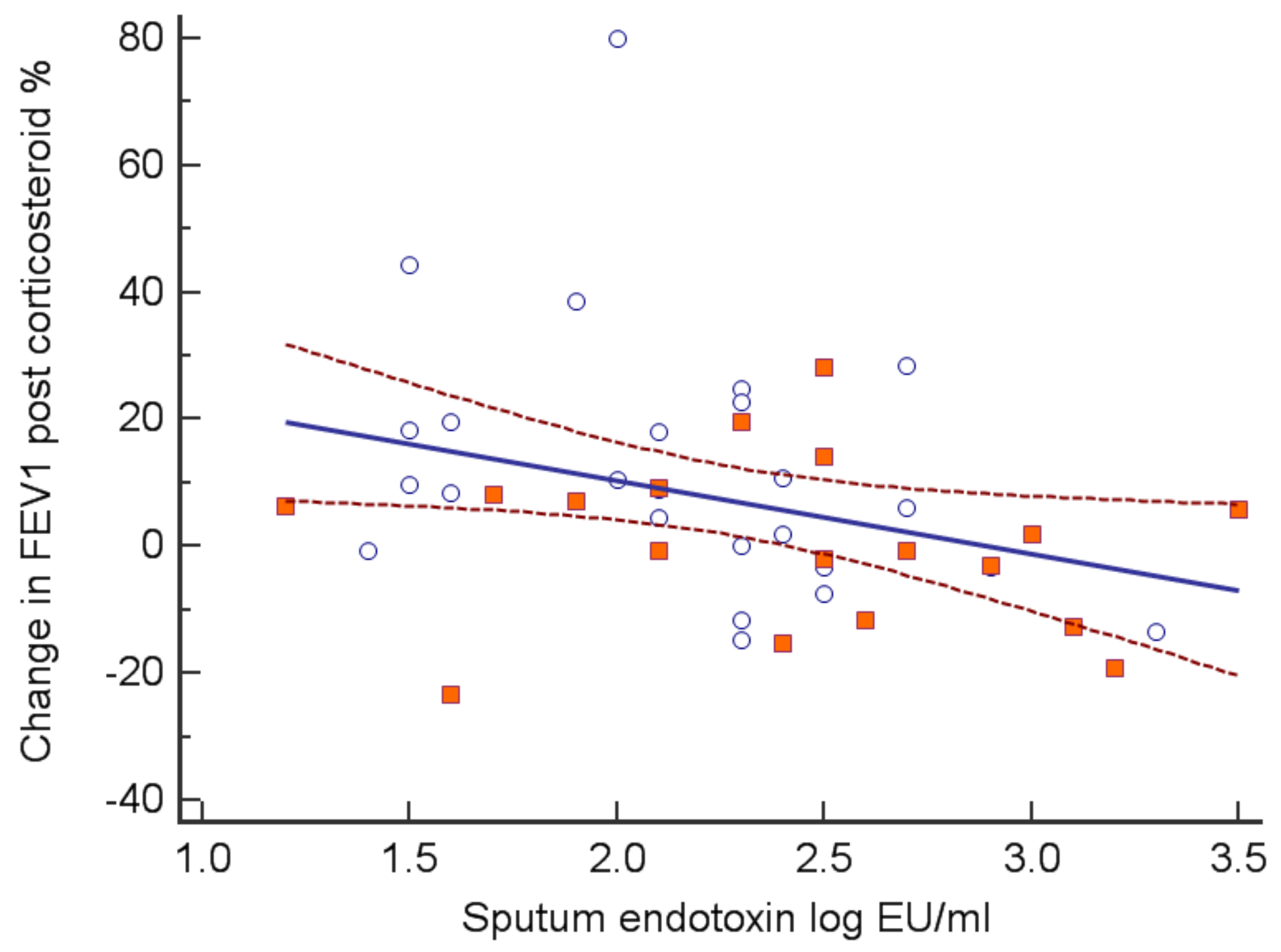

URL: https://mc.manuscriptcentral.com/errx Email: Joseph.Walsh@informa.com 


\section{Figure 3}

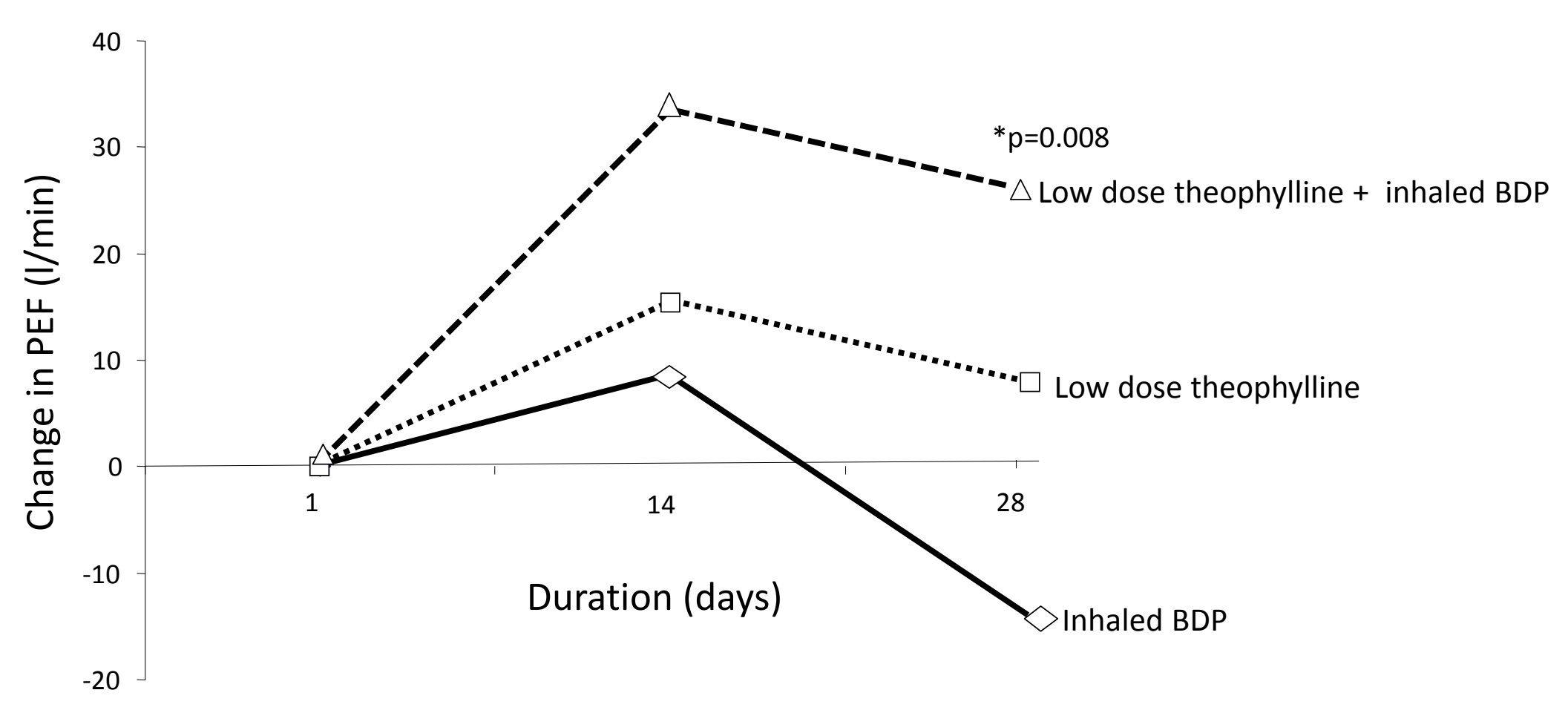

* $p$ value: $B D P$ + theophylline versus BDP alone 
Figure 4
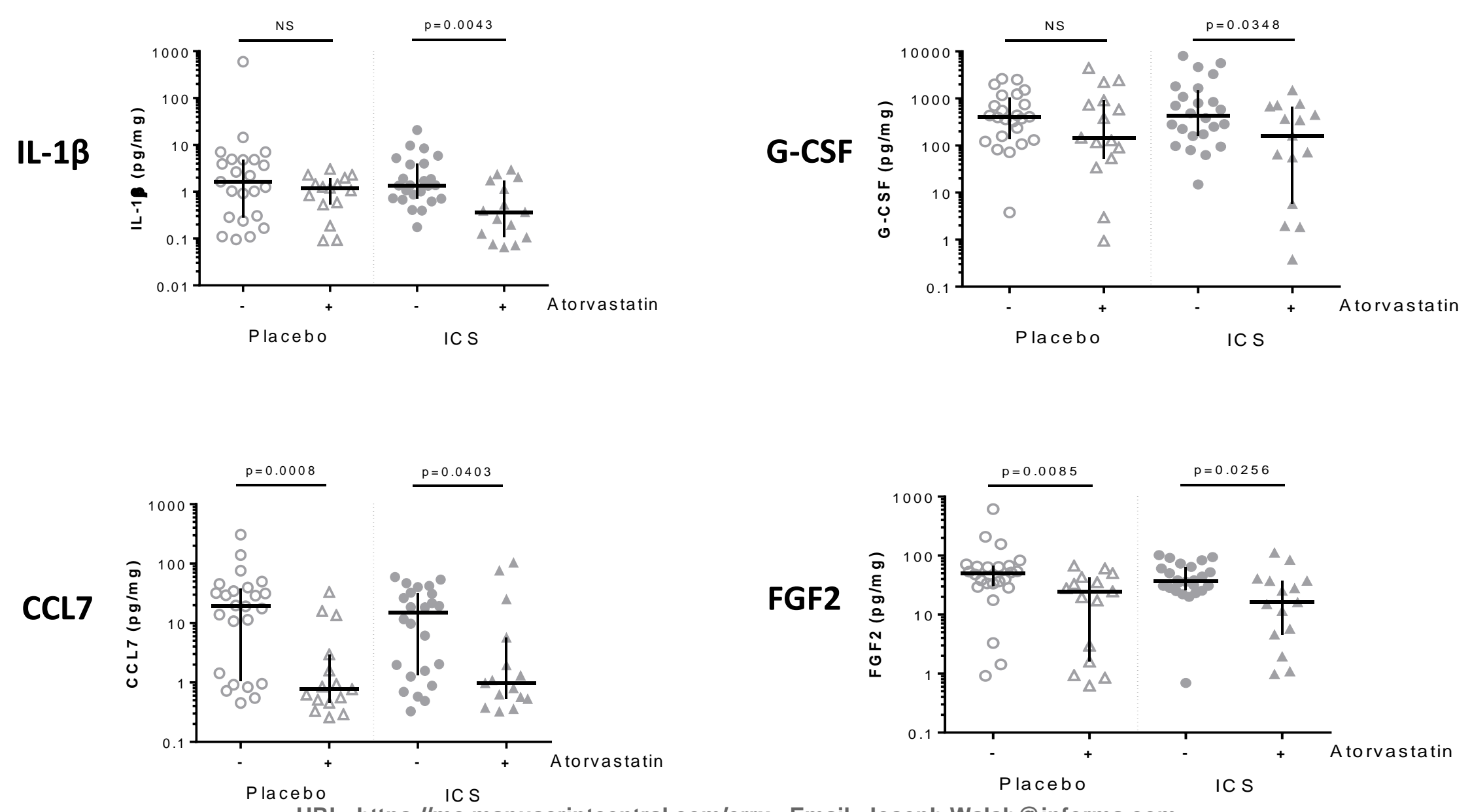

URL: https://mc.manuscriptcentral.com/errx Email: Joseph.Walsh@informa.com 


\section{RE: Permission to use figure from ERJ}

Kay Sharpe [Kay.Sharpe@ersj.org.uk] on behalf of permissions [permissions@ersj.org.uk]

Sent:27 November 2015 10:48

To: Neil Thomson

Effect of low-dose theophylline plus beclometasone on lung function in smokers with asthma: a pilot study M. Spears, I. Donnelly, L. Jolly, M. Brannigan, K. Ito, C. McSharry, J. Lafferty, R. Chaudhuri, G. Braganza, I. M. Adcock, P. J. Barnes, S. Wood, N. C. Thomson

European Respiratory Journal May 2009, 33 (5) 1010-1017; DOI: 10.1183/09031936.00158208

Material: Figure 2

European Respiratory Society hereby grants you permission to reproduce the material as requested and full acknowledgement must be given.

Acknowledgement Wording: This material has not been reviewed by European Respiratory Society prior to release; therefore the European Respiratory Society may not be responsible for any errors, omissions or inaccuracies, or for any consequences arising there from, in the content. Reproduced with permission of the European Respiratory Society @: European Respiratory Journal May 2009, 33 (5) 1010-1017; DOI: 10.1183/09031936.00158208

Title: Addressing corticosteroid in adults with asthma

Publication: Expert Review Respiratory Medicine

NLM Title Abbreviation: Expert Rev Respir Med

ISO Abbreviation: Expert Rev Respir Med

Author: Neil C Thomson

Publisher: Taylor \& Francis

Publication Format: Print and electronic

1747-6348 (Print)

1747-6356 (Electronic)

1747-6348 (Linking)

Terms \& Conditions:

Copyright remains with European Respiratory Society@. These publications are copyrighted material and must not be copied, reproduced, transferred, distributed, leased, licensed, placed in a storage retrieval system or publicly performed or used in any way except as specifically permitted in writing by the publishers (European Respiratory Society), as allowed under the terms and conditions of which it was purchased or as strictly permitted by applicable copyright law.

Reproduction of this is material is confined to the purpose and/or media for which permission is hereby given. Altering/Modifying Material: This is not permitted, however figures and illustrations maybe altered/adapted minimally to serve your work. Please be aware that the permission fee for the requested use of this material is waived in this instance but please be advised that your future requests for materials may attract a fee. This agreement is personal to you and may not be sublicense, assigned or transferred by you to any other person without our written permission.

URL: https://mc.manuscriptcentral.com/errx Email: Joseph.Walsh@informa.com 
Any unauthorised distribution or use of this text may be a direct infringement of the publisher's rights and those responsible may be liable in law accordingly.

This permission is granted for non-exclusive English world rights only.

Regards,

Kay

Kay Sharpe | European Respiratory Society | Publications Office | 442 Glossop Road | Sheffield | S10 2PX | UK

Main Tel: +44 1142672860 |Direct Tel: +44 1142672861 | Fax: +44 1142665064 | E-mail: kay.sharpe@ersj.org.uk

URL: https://mc.manuscriptcentral.com/errx Email: Joseph.Walsh@informa.com 


\section{COPYRIGHT TRANSFER ACREEMENT}

\section{informa}

Date: $27^{2}$ Nlov 2015 Contributor name: NEIL C THOMJON

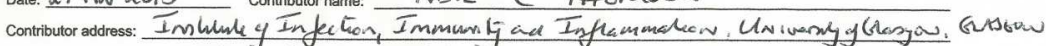
Manuscript number: ERRX-20:5 - 0097 Re: Manuscript entitled: Addressing corticostervid invermburty in aducts whth os thems. $\begin{array}{lll} & & \text { (the "Contribution") } \\ \text { For publication in } & \text { (the Joumal) }\end{array}$ $\begin{array}{lll}\text { Published by Informa UK Ltd. } & \text { ("Informa") }\end{array}$ Dear Contributor(s):

Thank you for submitting your Contrlbution for publication. In order to expodite the editing and publishing process and enable Informa to disseminate instructions for authors as soon as possible. If the Contribution is not accepted for publication, or if the Contribution is subsequentily rejected, this Agreement shall be null and void. Publication cannot proceed without a signed copy of this Agroement.

A. COPYRIGHT

1 The Contributor EITHER:

extensions or remewals, during the fill copyright tiom and of copyright and any

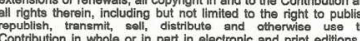

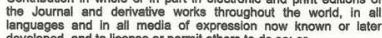

(b)

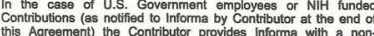
xclusive world-wide licence to pubish, republish, transmit, se electronic and print editions of the Joumal and in derivative works

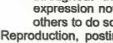
Reproduction, posting, transmission or other distribution or use of the
finel Contribution in whole or in part in any medium by the Contributor as permittod by this Agroement requires a citition to the Journal and an
appropriate credit to Informa as Publisher, andlor the Society
apolicable

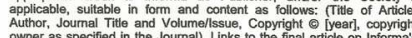
owner as specified in the Journal). Links to the final article on Informas

8. RETAINED RIGHTS

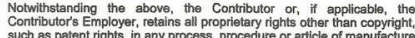
such as patent rights, in any procoss, procedure or article of manufactu
described in the Contribution. C. PERMITTED USES BY CONTRIBUTOR 1. Submitted Version. Informe licenses back the following rights to the

2.

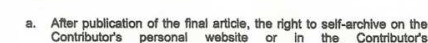

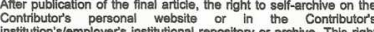

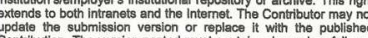

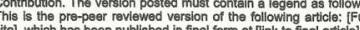
b. The right to transmit, print and share copies with colleagues.

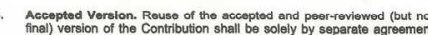
with Informa. Informa has agreements with cerriain funding agencise other offerings allowing open web use can be obtained firom your rnform
Editor. Nilt grantioes should check the box at the bottom of the Page 1 of 2
4. Final Publishod Version. Informa hereby licenses back to the
Contributor the following rights with respect to the final published version
of the Contribution:

a. Coples for colleagues. The personal inght of the Contributor only to

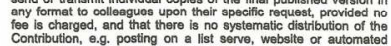
doelivery:

b. Reuse in other publications. The right to reuse the final
Contribution or parts theroof for any publication authored or editied

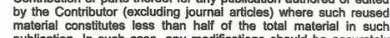
material constitutes less than half of the total material in such
publicaction. In such case, any modifications should be acourately
noted

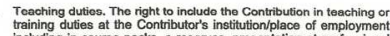

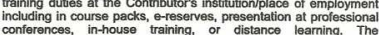
conftrences, in-house, trainhing, or distance learming. The
Contribution may not be used in seminars outside of normal toaching obligations (e.g. commorcial seminarse), Eloctronic posting

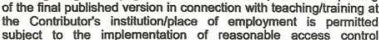

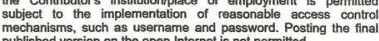

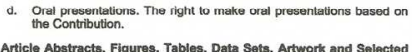

5. Arriclese Abstracte, Figures. Tables. Data Sats, Artwork and Selected
Text (up to 250 words).

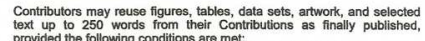

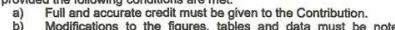

Otherwise, no changes may be mado.

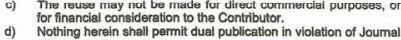

CONTRIBUTIONS OWNED BY EMPLOYER

1. If the Contribution was written by the Contributor in the course of the employment), the Contribution is oworked by the cormpanyiomployer which

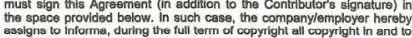

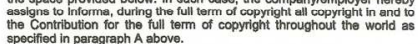

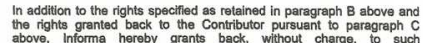

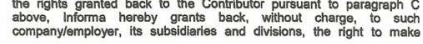

$215 \times 296 \mathrm{~mm}(200 \times 200$ DPI $)$

URL: https://mc.manuscriptcentral.com/errx Email: Joseph.Walsh@informa.com 


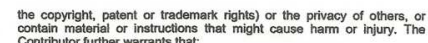

(a) whroverer possible and where appropriato any patient, client or

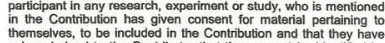
thenseselves, to be included in the Contribution and that they have
acknowiedged to the Contributor that they cannot be identifind by
the Contribution in any way; and

(b) they shall include in the

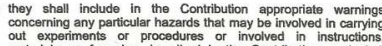
materials, or formulae described in the Contribution, and shal

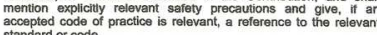
The Contributor undertakes to advise the Publisher if any part of the developments which might make it nececassary or advisisable for the Article

H. ASsiGnMENT Under this Agreement the Publisher may assign its rights or obligations
without the consont of the Contributor.

1. NO EMPLOYMENT

G. CONTRIBUTOR'S REPRESENTATIONS

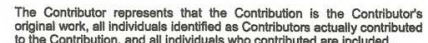

contributed are included.

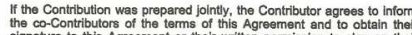
signature to this Agreorment or their written permission to sign on the
behalf. The Contribution is submitted only to this Journal and has

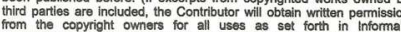

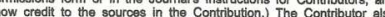

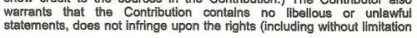

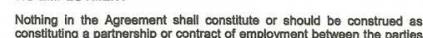

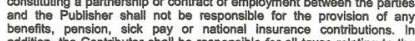
Contributor's services under this Agreemente and shall keep the Publisher

J. GOVERNING LAW Each Party to this Agreoment Irrevocably agroes that this Agroement is
construed under English law and submits to the non-exclusive

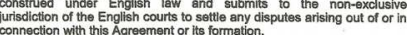

CHECK ONE BOX: Contributor-ownod work

Company/lnstitution-owned work (made-for-hire in the course of employment)

Company or institution (Employer-for-tire)

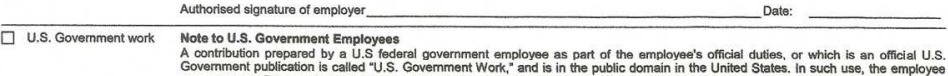

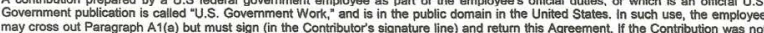
prepared as part of the employee's duties or is not an official U.S. Govermment publication, it is not a U.S. Government Work.

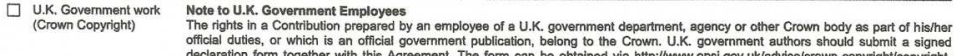

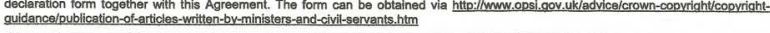

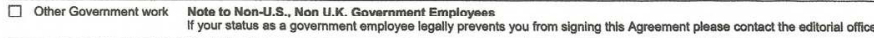

NIH Grantees
(Also check another box) Note to NIIH Grantees

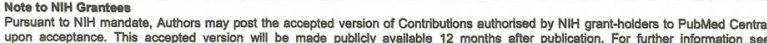

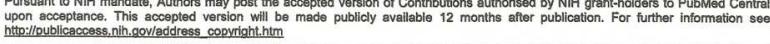
ALL CLASSES OF CONTRIBUTOR MUST SIGN HERE:

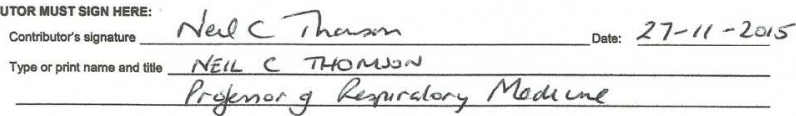

